\title{
Directive 2001/83/EC of the European Parliament and of the Council of 6 November 2001
}

\author{
On the Community code relating to medicinal products for human use
}

\section{THE EUROPEAN PARLIAMENT AND THE COUNCIL OF THE EURO- PEAN UNION,}

Having regard to the Treaty establishing the European Community, and in particular Article 95 thereof, Having regard to the proposal from the Commission; Having regard to the opinion of the Economic and Social Committee (1), Acting in accordance with the procedure laid down in Article 251 of the Treaty (2),

Whereas:

(1) Council Directive 65/65/EEC of 26 January 1965 on the approximation of provisions laid down by law, regulation or administrative action relating to medicinal products (3), Council Directive 75/318/EEC of 20 May 1975 on the approximation of the laws of Member States relating to analytical, pharmaco-toxicological and clinical standards and protocols in respect of the testing of proprietary medicinal products (4), Council Directive 75/319/EEC of 20 May 1975 on the approximation of provisions laid down by law, regulation or administrative action relating to proprietary medicinal products (5), Council Directive 89/342/EEC of 3 May 1989 extending the scope of Directives 65/65/EEC and 75/319/EEC and laying down additional provisions for immunological medicinal products consisting of vaccines, toxins or serums and allergens (6), Council Directive 89/343/EEC of 3 May 1989 extending the scope of Directives 65/65/EEC and 75/319/EEC and laying down additional provisions for radiopharmaceuticals (7), Council Directive 89/381/EEC of 14 June 1989 extending the scope of Directives 65/65/EEC and 75/319/EEC on the approximation of provisions laid down by law, regulation or administrative action relating to medicinal products and laying down special provisions for proprietary medicinal products derived from human blood or human plasma (8), Council Directive 92/25/EEC of 31 March 1992 on the wholesale distribution of medicinal products for human use (9), Council Directive 92/26/EEC of 31 March 1992 concerning the classification for the supply of medicinal products for human use (10), Council Directive 92/27/EEC of 31 March 1992 on the labelling of medicinal products for human use and on package leaflets (11), Council Directive 92/28/EEC of 31 March 1992 on the advertising of medicinal products for human use (12), Council Directive 92/73/EEC of 22 September 1992 
widening the scope of Directives 65/65/EEC and 75/319/EEC on the approximation of provisions laid down by law, regulation or administrative action relating to medicinal products and laying down additional provisions on homeopathic medicinal products (13) have been frequently and substantially amended. In the interests of clarity and rationality, the said Directives should therefore be codified by assembling them in a single text.

(2) The essential aim of any rules governing the production, distribution and use of medicinal products must be to safeguard public health.

(3) However, this objective must be attained by means which will not hinder the development of the pharmaceutical industry or trade in medicinal products within the Community.

(4) Trade in medicinal products within the Community is hindered by disparities between certain national provisions, in particular between provisions relating to medicinal products (excluding substances or combinations of substances which are foods, animal feeding-stuffs or toilet preparations), and such disparities directly affect the functioning of the internal market.

(5) Such hindrances must accordingly be removed; whereas this entails approximation of the relevant provisions.

(6) In order to reduce the disparities which remain, rules should be laid down on the control of medicinal products and the duties incumbent upon the Member States' competent authorities should be specified with a view to ensuring compliance with legal requirements.

28.11.2001 EN Official Journal of the European Communities L 311/67

(7) The concepts of harmfulness and therapeutic efficacy can only be examined in relation to each other and have only a relative significance depending on the progress of scientific knowledge and the use for which the medicinal product is intended. The particulars and documents which must accompany an application for marketing authorization for a medicinal product demonstrate that potential risks are outweighed by the therapeutic efficacy of the product.

(1) OJ C 368, 20.12.1999, p. 3.

(2) Opinion of the European Parliament of 3 July 2001 (not yet published in the Official Journal) and Council Decision of 27 September 2001.

(3) OJ 22, 9.2.1965, p. 369/65. Directive as last amended by Directive 93/39/EEC (OJ L 214, 24.8.1993, p. 22).

(4) OJ L 147, 9.6.1975, p. 1. Directive as last amended by Commission Directive 1999/83/EC (OJ L $243,15.9 .1999$, p. 9).

(5) OJ L 147, 9.6.1975, p. 13. Directive as last amended by Commission Directive 2000/38/EC (OJ L $139,10.6 .2000$, p. 28).
(6) OJ L 142, 25.5.1989, p. 14.
(7) OJ L 142, 25.5.1989, p. 16.
(8) OJ L 181, 28.6.1989, p. 44.
(9) OJ L 113, 30.4.1992, p. 1.
(10) OJ L 113, 30.4.1992, p. 5.
(11) OJ L 113, 30.4.1992, p. 8.
(12) OJ L 113, 30.4.1992, p. 13.
(13) OJ L 297, 13.10.1992, p. 8. 
(8) Standards and protocols for the performance of tests and trials on medicinal products are an effective means of control of these products and hence of protecting public health and can facilitate the movement of these products by laying down uniform rules applicable to tests and trials, the compilation of dossiers and the examination of applications.

(9) Experience has shown that it is advisable to stipulate more precisely the cases in which the results of toxicological and pharmacological tests or clinical trials do not have to be provided with a view to obtaining authorization for a medicinal product which is essentially similar to an authorized product, while ensuring that innovative firms are not placed at a disadvantage.

(10) However, there are reasons of public policy for not conducting repetitive tests on humans or animals without over-riding cause.

(11) The adoption of the same standards and protocols by all the Member States will enable the competent authorities to arrive at their decisions on the basis of uniform tests and by reference to uniform criteria and will therefore help to avoid differences in evaluation.

(12) With the exception of those medicinal products which are subject to the centralized Community authorization procedure established by Council Regulation (EEC) No 2309/93 of 22 July 1993 laying down Community procedures for the authorization and supervision of medicinal products for human and veterinary use and establishing a European Agency for the Evaluation of Medicinal Products (1) a marketing authorization for a medicinal product granted by a competent authority in one Member State ought to be recognized by the competent authorities of the other Member States unless there are serious grounds for supposing that the authorization of the medicinal product concerned may present a risk to public health. In the event of a disagreement between Member States about the quality, the safety or the efficacy of a medicinal product, a scientific evaluation of the matter should be undertaken according to a Community standard, leading to a single decision on the area of disagreement binding on the Member States concerned. Whereas this decision should be adopted by a rapid procedure ensuring close cooperation between the Commission and the Member States.

(13) For this purpose, a Committee for Proprietary Medicinal Products should be set up attached to the European Agency for the Evaluation of Medicinal Products established in the abovementioned Regulation (EEC) No 2309/93.

(14) This Directive represents an important step towards achievement of the objective of the free movement of medicinal products. Further measures may abolish any remaining barriers to the free movement of proprietary medicinal products will be necessary in the light of experience gained, particularly in the abovementioned Committee for Proprietary Medicinal Products.

(15) In order better to protect public health and avoid any unnecessary duplication of effort during the examination of application for a marketing authorization for medicinal products, Member States should systematically prepare assessment reports in respect of each medicinal product which is authorized by them, and exchange the 
reports upon request. Furthermore, a Member State should be able to suspend the examination of an application for authorization to place a medicinal product on the market which is currently under active consideration in another Member State with a view to recognizing the decision reached by the latter Member State.

(16) Following the establishment of the internal market, specific controls to guarantee the quality of medicinal products imported from third countries can be waived only if appropriate arrangements have been made by the Community to ensure that the necessary controls are carried out in the exporting country.

(17) It is necessary to adopt specific provisions for immunological medicinal products, homeopathic medicinal products, radiopharmaceuticals, and medicinal products based on human blood or human plasma.

(18) Any rules governing radiopharmaceuticals must take into account the provisions of Council Directive 84/466/Euratom of 3 September 1984 laying down basic measures for the radiation protection of persons undergoing medical examination or treatment (2). Account should also be taken of Council Directive 80/836/Euratom of 15 July 1980 amending the Directives laying down the basic safety standards for the health protection of the general public and workers.

L 311/68 EN Official Journal of the European Communities 28.11.2001 against the dangers of ionizing radiation (1), the objective of which is to prevent the exposure of workers or patients to excessive or unnecessarily high levels of ionizing radiation, and in particular of Article 5c thereof, which requires prior authorization for the addition of radioactive substances to medicinal products as well as for the importation of such medicinal products.

(19) The Community entirely supports the efforts of the Council of Europe to promote voluntary unpaid blood and plasma donation to attain self-sufficiency throughout the Community in the supply of blood products, and to ensure respect for ethical principles in trade in therapeutic substances of human origin.

(20) The rules designed to guarantee the quality, safety and efficacy of medicinal products derived from human blood or human plasma must be applied in the same manner to both public and private establishments, and to blood and plasma imported from third countries.

(21) Having regard to the particular characteristics of these homeopathic medicinal products, such as the very low level of active principles they contain and the difficulty of applying to them the conventional statistical methods relating to clinical trials, it is desirable to provide a special, simplified registration procedure for those homeopathic medicinal products which are placed on the market without therapeutic indications in a pharmaceutical form and dosage which do not present a risk for the patient.

(22) The anthroposophic medicinal products described in an official pharmacopoeia and prepared by a homeopathic method are to be treated, as regards registr-

(1) OJ L 214, 24.8.1993, p. 1. Regulation as amended by Commission Regulation (EC) No 649/98 (OJ L 88, 24.3.1998, p. 7).

(2) OJ L 265, 5.10.1984, p. 1. Directive repealed with effect from 13 May 2000 by Directive 97/43/Euratom (OJ L 180, 9.7.1997, p. 22). 
ation and marketing authorization, in the same way as homeopathic medicinal products.

(23) It is desirable in the first instance to provide users of these homeopathic medicinal products with a very clear indication of their homeopathic character and with sufficient guarantees of their quality and safety.

(24) The rules relating to the manufacture, control and inspection of homeopathic medicinal products must be harmonized to permit the circulation throughout the Community of medicinal products which are safe and of good quality.

(25) The usual rules governing the authorization to market medicinal products should be applied to homeopathic medicinal products placed on the market with therapeutic indications or in a form which may present risks which must be balanced against the desired therapeutic effect. In particular, those Member States which have a homeopathic tradition should be able to apply particular rules for the evaluation of the results of tests and trials intended to establish the safety and efficacy of these medicinal products provided that they notify them to the Commission.

(26) In order to facilitate the movement of medicinal products and to prevent the controls carried out in one Member State from being repeated in another, minimum requirements should be laid down for manufacture and imports coming from third countries and for the grant of the authorization relating thereto.

(27) It should be ensured that, in the Member States, the supervision and control of the manufacture of medicinal products is carried out by a person who fulfils minimum conditions of qualification.

(28) Before an authorization to market an immunological medicinal product or derived from human blood or human plasma can be granted, the manufacturer must demonstrate his ability to attain batch-to-batch consistency. Before an authorization to market a medicinal product derived from human blood or human plasma can be granted, the manufacturer must also demonstrate the absence of specific viral contamination, to the extent that the state of technology permits.

(29) The conditions governing the supply of medicinal products to the public should be harmonized.

(30) In this connection persons moving around within the Community have the right to carry a reasonable quantity of medicinal products lawfully obtained for their personal use. It must also be possible for a person established in one Member State to receive from another Member State a reasonable quantity of medicinal products intended for his personal use.

(31) In addition, by virtue of Regulation (EC) No 2309/93, certain medicinal products are the subject of a Community marketing authorization. In this context, the classification for the supply of medicinal products covered by a Community marketing authorization needs to be established. It is therefore important to set the criteria on the basis of which Community decisions will be taken.

(32) It is therefore appropriate, as an initial step, to harmonize the basic principles applicable to the classification for the supply of medicinal products in the Community or in the Member State concerned, while taking as a starting point the principles 
already established on this subject by the Council of Europe as well as the work of harmonization completed within the framework of the United Nations, concerning narcotic and psychotropic substances.

28.11.2001 EN Official Journal of the European Communities L 311/69

(33) The provisions dealing with the classification of medicinal products for the purpose of supply do not infringe the national social security arrangements for reimbursement or payment for medicinal products on prescription.

(34) Many operations involving the wholesale distribution of medicinal products for human use may cover several Member States simultaneously.

(35) It is necessary to exercise control over the entire chain of distribution of medicinal products, from their manufacture or import into the Community through to supply to the public, so as to guarantee that such products are stored, transported and handled in suitable conditions. The requirements which must be adopted for this purpose will considerably facilitate the withdrawal of defective products from the market and allow more effective efforts against counterfeit products.

(36) Any person involved in the wholesale distribution of medicinal products should be in possession of a special authorization. Pharmacists and persons authorized to supply medicinal products to the public, and who confine themselves to this activity, should be exempt from obtaining this authorization. It is however necessary, in order to control the complete chain of distribution of medicinal products, that pharmacists and persons authorized to supply medicinal products to the public keep records showing transactions in products received.

(37) Authorization must be subject to certain essential conditions and it is the responsibility of the Member State concerned to ensure that such conditions are met; whereas each Member State must recognize authorizations granted by other Member States.

(38) Certain Member States impose on wholesalers who supply medicinal products to pharmacists and on persons authorized to supply medicinal products to the public certain public service obligations. Those Member States must be able to continue to impose those obligations on wholesalers established within their territory. They must also be able to impose them on wholesalers in other Member States on condition that they do not impose any obligation more stringent than those which they impose on their own wholesalers and provided that such obligations may be regarded as warranted on grounds of public health protection and are proportionate in relation to the objective of such protection.

(39) Rules should be laid down as to how the labelling and package leaflets are to be presented.

(40) The provisions governing the information supplied to users should provide a high degree of consumer protection, in order that medicinal products may be used correctly on the basis of full and comprehensible information.

(1) OJ L 246, 17.9.1980, p. 1. Directive as amended by Directive 84/467/Euratom (OJ L 265, 5.10.1984, p. 4), repealed with effect from 13 May 2000 by Directive 96/29/Euratom (OJ L 314, 4.12.1996, p. 20). 
(41) The marketing of medicinal products whose labelling and package leaflets comply with this Directive should not be prohibited or impeded on grounds connected with the labelling or package leaflet.

(42) This Directive is without prejudice to the application of measures adopted pursuant to Council Directive 84/450/EEC of 10 September 1984 relating to the approximation of the laws, regulations and administrative provisions of the Member States concerning misleading advertising (1).

(43) All Member States have adopted further specific measures concerning the advertising of medicinal products. There are disparities between these measures. These disparities are likely to have an impact on the functioning of the internal market, since advertising disseminated in one Member State is likely to have effects in other Member States.

(44) Council Directive 89/552/EEC of 3 October 1989 on the coordination of certain provisions laid down by law, regulation or administrative action in Member States concerning the pursuit of television broadcasting activities (2) prohibits the television advertising of medicinal products which are available only on medical prescription in the Member State within whose jurisdiction the television broadcaster is located. This principle should be made of general application by extending it to other media.

(45) Advertising to the general public, even of non-prescription medicinal products, could affect public health, were it to be excessive and ill-considered. Advertising of medicinal products to the general public, where it is permitted, ought therefore to satisfy certain essential criteria which ought to be defined.

(46) Furthermore, distribution of samples free of charge to the general public for promotional ends must be prohibited.

(47) The advertising of medicinal products to persons qualified to prescribe or supply them contributes to the information available to such persons. Nevertheless, this advertising should be subject to strict conditions and effective monitoring, referring in particular to the work carried out within the framework of the Council of Europe.

(48) Advertising of medicinal products should be subject to effective, adequate monitoring. Reference in this regard should be made to the monitoring mechanisms set up by Directive 84/450/EEC.

(49) Medical sales representatives have an important role in the promotion of medicinal products. Therefore, certain obligations should be imposed upon them, in particular the obligation to supply the person visited with a summary of product characteristics.

L 311/70 EN Official Journal of the European Communities 28.11.2001

(50) Persons qualified to prescribe medicinal products must be able to carry out these functions objectively without being influenced by direct or indirect financial

(1) OJ L 250, 19.9.1984, p. 17. Directive as amended by Directive 97/55/EC (OJ L 290, 23.10.1997, p. 18)

(2) OJ L 298, 17.10.1989, p. 23. Directive as amended by Directive 97/36/EC (OJ L 202, 30.7.1997, p. 60) 
inducements.

(51) It should be possible within certain restrictive conditions to provide samples of medicinal products free of charge to persons qualified to prescribe or supply them so that they can familiarize themselves with new products and acquire experience in dealing with them.

(52) Persons qualified to prescribe or supply medicinal products must have access to a neutral, objective source of information about products available on the market. Whereas it is nevertheless for the Member States to take all measures necessary to this end, in the light of their own particular situation.

(53) Each undertaking which manufactures or imports medicinal products should set up a mechanism to ensure that all information supplied about a medicinal product conforms with the approved conditions of use.

(54) In order to ensure the continued safety of medicinal products in use, it is necessary to ensure that pharmacovigilance systems in the Community are continually adapted to take account of scientific and technical progress.

(55) It is necessary to take account of changes arising as a result of international harmonisation of definitions, terminology and technological developments in the field of pharmacovigilance.

(56) The increasing use of electronic networks for communication of information on adverse reactions to medicinal products marketed in the Community is intended to allow competent authorities to share the information at the same time.

(57) It is the interest of the Community to ensure that the pharmacovigilance systems for centrally authorised medicinal products and those authorised by other procedures are consistent.

(58) Holders of marketing authorisations should be proactively responsible for on-going pharmacovigilance of the medicinal products they place on the market.

(59) The measures necessary for the implementation of this Directive should be adopted in accordance with Council Decision 1999/468/EC of 28 June 1999 laying down the procedures for the exercise of implementing powers conferred on the Commission (1).

(60) The Commission should be empowered to adopt any necessary changes to Annex I in order to take into account scientific and technical progress.

(61) This Directive should be without prejudice to the obligations of the Member States concerning the time-limits for transposition of the Directives set out in

Annex II, Part B.

\section{HAVE ADOPTED THIS DIRECTIVE:}

\section{TITLE I}

\section{DEFINITIONS}

Article 1 
For the purposes of this Directive, the following terms shall bear the following meanings:

1. Proprietary medicinal product: Any ready-prepared medicinal product placed on the market under a special name and in a special pack.

2. Medicinal product: Any substance or combination of substances presented for treating or preventing disease in human beings. Any substance or combination of substances which may be administered to human beings with a view to making a medical diagnosis or to restoring, correcting or modifying physiological functions in human beings is likewise considered a medicinal product.

3. Substance:

Any matter irrespective of origin which may be:

- human, e.g. human blood and human blood products;

- animal, e.g. micro-organisms, whole animals, parts of organs, animal secretions, toxins, extracts, blood products;

- vegetable, e.g. micro-organisms, plants, parts of plants, vegetable secretions, extracts;

- chemical, e.g.

elements, naturally occurring chemical materials and chemical products obtained by chemical change or

28.11.2001 EN Official Journal of the European Communities L 311/71

4. Immunological medicinal product:

Any medicinal product consisting of vaccines, toxins, serums or allergen products:

(a) vaccines, toxins and serums shall cover in particular:

(i) agents used to produce active immunity, such as cholera vaccine, BCG, polio vaccines, smallpox vaccine;

(ii) agents used to diagnose the state of immunity, including in particular tuberculin and tuberculin PPD, toxins for the Schick and Dick Tests, brucellin;

(iii) agents used to produce passive immunity, such as diphtheria antitoxin, antismallpox globulin, antilymphocytic globulin;

(b) allergen product. shall mean any medicinal product which is intended to identify or induce a specific acquired alteration in the immunological response to an allergizing agent.

5. Homeopathic medicinal product:

Any medicinal product prepared from products, substances or compositions called homeopathic stocks in accordance with a homeopathic manufacturing procedure described by the European Pharmacopoeia or, in absence thereof, by the pharmacopoeias currently used officially in the Member States. A homeopathic medicinal product may also contain a number of principles.

(1) OJ L 184, 17.7.1999, p. 23. synthesis. 
6. Radiopharmaceutical:

Any medicinal product which, when ready for use, contains one or more radionuclides (radioactive isotopes) included for a medicinal purpose.

7. Radionuclide generator:

Any system incorporating a fixed parent radionuclide from which is produced a daughter radionuclide which is to be obtained by elution or by any other method and used in a radiopharmaceutical.

8. Radionuclide kit:

Any preparation to be reconsitituted or combined with radionuclides in the final radiopharmaceutical, usually prior to its administration.

9. Radionuclide precursor:

Any other radionuclide produced for the radio-labelling of another substance prior to administration.

10. Medicinal products derived from human blood or human plasma:

Medicinal products based on blood constitutents which are prepared industrially by public or private establishments, such medicinal products including, in particular, albumin, coagulating factors and immunoglobulins of human origin.

11. Adverse reaction:

A response to a medicinal product which is noxious and unintended and which occurs at doses normally used in man for the prophylaxis, diagnosis or therapy of disease or for the restoration, correction or modification of physiological function.

12. Serious adverse reaction:

An adverse reaction which results in death, is life-threatening, requires inpatient hospitalisation or prolongation of existing hospitalisation, results in persistent or significant disability or incapacity, or is a congenital anomaly/birth defect.

13. Unexpected adverse reaction:

An adverse reaction, the nature, severity or outcome of which is not consistent with the summary of product characteristics.

14. Periodic safety update reports:

The periodical reports containing the records referred to in Article 104.

15. Post-authorisation safety study:

A pharmacoepidemiological study or a clinical trial carried out in accordance with the terms of the marketing authorisation, conducted with the aim of identifying or quantifying a safety hazard relating to an authorised medicinal product.

16. Abuse of medicinal products:

Persistent or sporadic, intentional excessive use of medicinal products which is accompanied by harmful physical or psychological effets. L 311/72 EN Official Journal of the European Communities 28.11.2001

17. Wholesale distribution of medicinal products:

All activities consisting of procuring, holding, supplying or exporting medicinal products, apart from supplying medicinal products to the public. Such activities are carried out with manufacturers or their depositories, importers, other wholesale 
distributors or with pharmacists and persons authorized or entitled to supply medicinal products to the public in the Member State concerned.

18. Public service obligation:

The obligation placed on wholesalers to guarantee permanently an adequate range of medicinal products to meet the requirements of a specific geographical area and to deliver the supplies requested within a very short time over the whole of the area in question.

19. Medicinal Prescription:

Any medicinal prescription issued by a professional person qualified to do so.

20. Name of the medicinal product:

The name given to a medicinal product, which may be either an invented name or a common or scientific name, together with a trade mark or the name of the manufacturer; the invented name shall not be liable to confusion with the common name.

21. Common name:

The international non-proprietary name recommended by the World Health Organization, or, if one does not exist, the usual common name.

22. Strength of the medicinal product:

The content of the active substances expressed quantitatively per dosage unit, per unit of volume or weight according to the dosage form.

23. Immediate packaging:

The container or other form of packaging immediately in contact with the medicinal product.

24. Outer packaging:

The packaging into which is placed the immediate packaging.

25. Labelling:

Information on the immediate or outer packaging.

26. Package leaflet:

A leaflet containing information for the user which accompanies the medicinal product.

27. Agency:

The European Agency for the Evaluation of Medicinal Products established by Regulation (EEC) No 2309/93.

28. Risk to public health:

All risks with regard to the quality, safety and efficacy of the medicinal product.

TITLE II

SCOPE

Article 2

The provisions of this Directive shall apply to industrially produced medicinal products for human use intended to be placed on the market in Member States.

Article 3

This Directive shall not apply to: 
1. Any medicinal product prepared in a pharmacy in accordance with a medical prescription for an individual patient (commonly known as the magistral formula).

2. Any medicinal product which is prepared in a pharmacy in accordance with the prescriptions of a pharmacopoeia and is intended to be supplied directly to the patients served by the pharmacy in question (commonly known as the official formula).

3. Medicinal products intended for research and development trials.

4. Intermediate products intended for further processing by an authorized manufacturer.

5. Any radionuclides in the form of sealed sources.

6. Whole blood, plasma or blood cells of human origin.

Article 4

1. Nothing in this Directive shall in any way derogate from the Community rules for the radiation protection of persons undergoing medical examination or treatment, or from the Community rules laying down the basic safety standards for the health protection of the general public and workers against the dangers of ionizing radiation. 28.11.2001 EN Official Journal of the European Communities L 311/73

2. This Directive shall be without prejudice to Council Decision 86/346/EEC of 25 June 1986 accepting on behalf of the Community the European Agreement on the Exchange of Therapeutic Substances of Human Origin (1).

3. The provisions of this Directive shall not affect the powers of the Member States' authorities either as regards the setting of prices for medicinal products or their inclusion in the scope of national health insurance schemes, on the basis of health, economic and social conditions.

4. This Directive shall not affect the application of national legislation prohibiting or restricting the sale, supply or use of medicinal products as contraceptives or abortifacients. The Member States shall communicate the national legislation concerned to the Commission.

Article 5

A Member State may, in accordance with legislation in force and to fulfil special needs, exclude from the provisions of this Directive medicinal products supplied in response to a bona fide unsolicited order, formulated in accordance with the specifications of an authorized health care professional and for use by his individual patients on his direct personal responsibility.

TITLE III

PLACING ON THE MARKET

CHAPTER 1

Marketing authorization

Article 6

1. No medicinal product may be placed on the market of a Member State unless a marketing authorization has been issued by the competent authorities of that Member State in accordance with this Directive or an authorization has been granted in accordance with Regulation (EEC) No 2309/93. 
2. The authorisation referred to in paragraph 1 shall also be required for radionuclide generators, radionuclide kits, radionuclide precursor radiopharmaceuticals and industrially prepared radiopharmaceuticals.

Article 7

A marketing authorization shall not be required for a radiopharmaceutical prepared at the time of use by a person or by an establishment authorized, according to national legislation, to use such medicinal products in an approved health care establishment exclusively from authorized radionuclide generators, radionuclide kits or radionuclide precursors in accordance with the manufacturer's instructions.

Article 8

1. In order to obtain an authorization to place a medicinal product on the market regardless of the procedure established by Regulation (EEC) No 2309/93, an application shall be made to the competent authority of the Member State concerned.

2. A marketing authorization may only be granted to an applicant established in the Community.

3. The application shall be accompanied by the following particulars and documents, submitted in accordance with

Annex I:

(a) Name or corporate name and permanent address of the applicant and, where applicable, of the manufacturer.

(b) Name of the medicinal product.

(c) Qualitative and quantitative particulars of all the constituents of the medicinal product in usual terminology, but excluding empirical chemical formulae, with mention of the international non-proprietary name recommended by the World Health Organization where such name exists.

(d) Description of the manufacturing method.

(e) Therapeutic indications, contra-indications and adverse reactions.

(f) Posology, pharmaceutical form, method and route of administration and expected shelf life.

(g) If applicable, reasons for any precautionary and safety measures to be taken for the storage of the medicinal product, its administration to patients and for the disposal of waste products, together with an indication of any potential risks presented by the medicinal product for the environment.

(h) Description of the control methods employed by the manufacturer (qualitative and quantitative analysis of the constituents and of the finished product, special tests, e.g. sterility tests, tests for the presence of pyrogenic substances, the presence of heavy metals, stability tests, biological and toxicity tests, controls carried out at an intermediate stage of the manufacturing process).

(i) Results of:

- physico-chemical, biological or microbiological tests,

(1) OJ L 207, 30.7.1986, p. 1. . clinical trials. 
- toxicological and pharmacological tests,

L 311/74 EN Official Journal of the European Communities 28.11.2001

(j) A summary, in accordance with Article 11, of the product characteristics, one or more specimens or mock-ups of the outer packaging and the immediate packaging of the medicinal product, together with a package leaflet.

(k) A document showing that the manufacturer is authorised in his own country to produce medicinal products.

(l) Copies of any authorisation obtained in another Member State or in a third country to place the medicinal product on the market, together with a list of those Member States in which an application for authorisation submitted in accordance with this Directive is under examination. Copies of the summary of the product characteristics proposed by the applicant in accordance with Article 11 or approved by the competent authorities of the Member State in accordance with Article 21. Copies of the package leaflet proposed in accordance with Article 59 or approved by the competent authorities of the Member State in accordance with Article 61. Details of any decision to refuse authorization, whether in the Community or in a third country, and the reasons for such a decision. This information shall be updated on a regular basis.

Article 9

In addition to the requirements set out in Articles 8 and 10(1), an application for authorization to market a radionuclide generator shall also contain the following information and particulars:

- a general description of the system together with a detailed description of the components of the system which may affect the composition or quality of the daughter nucleid preparation,

- qualitative and quantitative particulars of the eluate or the sublimate.

Article 10

1. In derogation of Article 8(3)(i), and without prejudice to the law relating to the protection of industrial and commercial property:

(a) The applicant shall not be required to provide the results of toxicological and pharmacological tests or the results of clinical trials if he can demonstrate:

(i) either that the medicinal product is essentially similar to a medicinal product authorized in the Member State concerned by the application and that the holder of the marketing authorization for the original medicinal product has consented to the toxicological, pharmacological and/or clinical references contained in the file on the original medicinal product being used for the purpose of examining the application in question;

(ii) or that the constituent or constituents of the medicinal product have a well established medicinal use, with recognized efficacy and an acceptable level of safety, by means of a detailed scientific bibliography; 
(iii) or that the medicinal product is essentially similar to a medicinal product which has been authorized within the Community, in accordance with Community provisions in force, for not less than six years and is marketed in the Member State for which the application is made. This period shall be extended to 10 years in the case of high-technology medicinal products having been authorised according to the procedure laid down in Article 2(5) of Council Directive 87/22/EEC (1). Furthermore, a Member State may also extend this period to 10 years by a single Decision covering all the medicinal products marketed on its territory where it considers this necessary in the interest of public health. Member States are at liberty not to apply the six-year period beyond the date of expiry of a patent protecting the original medicinal product. However, where the medicinal product is intended for a different therapeutic use from that of the other medicinal products marketed or is to be administered by different routes or in different doses, the results of appropriate toxicological and pharmacological tests and/or of appropriate clinical trials must be provided.

(b) In the case of new medicinal products containing known constituents not hitherto used in combination for therapeutic purposes, the results of toxicological and pharmacological tests and of clinical trials relating to that combination must be provided, but it shall not be necessary to provide references relating to each individual constituent.

2. Annex I shall apply by analogy where, pursuant to point (ii) of paragraph 1, (a), bibliographic references to published data are submitted.

Article 11

The summary of the product characteristics shall contain the following information:

1. Name of the medicinal product.

2. Qualitative and quantitative composition in terms of the active substances and constituents of the excipient, knowledge of which is essential for proper administration of the medicinal product. The usual common name or chemical description shall be used.

93/41/EEC (OJ L 214, 24.8.1993, p. 40).

28.11.2001 EN Official Journal of the European Communities L 311/75

3. Pharmaceutical form.

4. Pharmacological properties and, in so far as this information is useful for therapeutic purposes, pharmacokinetic particulars.

5. Clinical particulars:

5.1. therapeutic indications,

5.2. contra-indications,

5.3. adverse reactions (frequency and seriousness),

5.4. special precautions for use and, in the case of immunological medicinal products, any special precautions to be taken by persons handling such products and

(1) OJ L 15, 17.1.1987, p. 38. Directive repealed by Directive 
administering them to patients, together with any precautions to be taken by the patient,

5.5. use during pregnancy and lactation,

5.6. interaction with other medicaments and other forms of interaction,

5.7. posology and method of administration for adults and, where necessary, for children,

5.8. overdose (symptoms, emergency procedures, antidotes),

5.9. special warnings,

5.10. effects on ability to drive and to use machines.

6. Pharmaceutical particulars:

6.1. major incompatibilities,

6.2. shelf life, when necessary after reconstitution of the medicinal product or when the immediate packaging is opened for the first time,

6.3. special precautions for storage,

6.4. nature and contents of the immediate packaging,

6.5. special precautions for disposal of unused medicinal products or waste materials derived from such medicinal products, if appropriate.

7. Name or corporate name and permanent address of the marketing authorization holder.

8. For radiopharmaceuticals, full details of internal radiation dosimetry.

9. For radiopharmaceuticals, additional detailed instructions for extemporaneous preparation and quality control of such preparation and, where appropriate, maximum storage time during which any intermediate preparation such as an eluate or the readyto-use pharmaceutical will conform with its specifications.

Article 12

1. Member States shall take all appropriate measures to ensure that the documents and particulars listed in Article 8(3)(h) and (i), and Article 10(1)(a)(ii) are drawn up by experts with the necessary technical or professional qualifications before they are submitted to the competent authorities. These documents and particulars shall be signed by the experts.

2. The duties of the experts according to their respective qualifications shall be:

(a) to perform tasks falling within their respective disciplines (analysis, pharmacology and similar experimental sciences, clinical trials) and to describe objectively the results obtained (qualitatively and quantitatively);

(b) to describe their observations in accordance with Annex I, and to state, in particular:

- in the case of the analyst, whether the medicinal product is consistent with the declared composition, giving any substantiation of the control methods employed by the manufacturer;

- in the case of the pharmacologist or the specialist with similar experimental competence, the toxicity of the medicinal product and the pharmacological properties observed; 
- in the case of the clinician, whether he has been able to ascertain effects on persons treated with the medicinal product which correspond to the particulars given by the applicant in accordance with Articles 8 and 10, whether the patient tolerates the medicinal product well, the posology the clinician advises and any contra-indications and adverse reactions;

(c) where applicable, to state the grounds for using the bibliography mentioned in point (a)(ii) of Article 10(1). 3. Detailed reports by the experts shall form part of the particulars accompanying the application which the applicant submits to the competent authorities.

\section{CHAPTER 2}

Specific provisions applicable to homeopathic medicinal products

Article 13

1. Member States shall ensure that homeopathic medicinal products manufactured and placed on the market within the L 311/76 EN Official Journal of the European Communities 28.11.2001 Community are registered or authorized in accordance with Articles 14, 15 and 16, except where the products are covered by a registration or authorization which was granted under national law on or before 31 December 1993 (and whether or not that registration or authorization has been renewed after that date). Each Member State shall take due account of registrations and authorizations previously granted by another Member State.

2. A Member State may refrain from establishing a special, simplified registration procedure for the homeopathic medicinal products referred to in Article 14. A Member State shall inform the Commission accordingly. The Member State concerned shall allow the use in its territory of homeopathic medicinal products registered by other Member States in accordance with Articles 14 and 15.

Article 14

1. Only homeopathic medicinal products which satisfy all of the following conditions may be subject to a special, simplified registration procedure:

- they are administered orally or externally,

- no specific therapeutic indication appears on the labelling of the medicinal product or in any information relating thereto,

- there is a sufficient degree of dilution to guarantee the safety of the medicinal product; in particular, the medicinal product may not contain either more than one part per 10000 of the mother tincture or more than 1/100th of the smallest dose used in allopathy with regard to active substances whose presence in an allopathic medicinal product results in the obligation to submit a doctor's prescription.

At the time of registration, Member States shall determine the classification for the dispensing of the medicinal product.

2. The criteria and rules of procedure provided for in Article 4(4), Article 17(1) and Articles 22 to 26, 112, 116 and 125 shall apply by analogy to the special, simplified registration procedure for homeopathic medicinal products, with the exception of the proof of therapeutic efficacy. 
3. The proof of therapeutic efficacy shall not be required for homeopathic medicinal products registered in accordance with paragraph 1 of this Article, or, where appropriate, admitted in accordance with Article 13(2).

Article 15

An application for special, simplified registration may cover a series of medicinal products derived from the same homeopathic stock or stocks. The following documents shall be included with the application in order to demonstrate, in particular, the pharmaceutical quality and the batch-to-batch homogeneity of the products concerned:

- scientific name or other name given in a pharmacopoeia of the homeopathic stock or stocks, together with a statement of the various routes of administration, pharmaceutical forms and degree of dilution to be registered,

- dossier describing how the homeopathic stock or stocks is/are obtained and controlled, and justifying its/their homeopathic nature, on the basis of an adequate bibliography,

- manufacturing and control file for each pharmaceutical form and a description of the method of dilution and potentization,

- manufacturing authorization for the medicinal product concerned,

- copies of any registrations or authorizations obtained for the same medicinal product in other Member States,

- one or more specimens or mock-ups of the outer packaging and the immediate packaging of the medicinal products to be registered,

- data concerning the stability of the medicinal product.

Article 16

1. Homeopathic medicinal products other than those referred to in Article 14(1) shall be authorized and labelled in accordance with Articles 8, 10 and 11.

2. A Member State may introduce or retain in its territory specific rules for the toxicological and pharmacological tests and clinical trials of homeopathic medicinal products other than those referred to in Article 14(1) in accordance with the principles and characteristics of homeopathy as practised in that Member State. In this case, the Member State concerned shall notify the Commission of the specific rules in force.

3. Title IX shall apply to homeopathic medicinal products, with the exception of those referred to in Article 14(1).

CHAPTER 3

Procedures relevant to the marketing authorization

Article 17

1. Member States shall take all appropriate measures to ensure that the procedure for granting an authorization to place a medicinal product on the market is completed within 210 days of the submission of a valid application. 28.11.2001 EN Official Journal of the European Communities L 311/77

2. Where a Member State notes that an application for authorization is already under active examination in another Member State in respect of that medicinal product, the Member State concerned may decide to suspend the detailed examination of 
the application in order to await the assessment report prepared by the other Member State in accordance with Article 21(4). The Member State concerned shall inform the other Member State and the applicant of its decision to suspend detailed examination of the application in question. As soon as it has completed the examination of the application and reached a decision, the other Member State shall forward a copy of its assessment report to the Member State concerned.

Article 18

Where a Member State is informed in accordance with Article 8(3)(1) that another Member State has authorized a medicinal product which is the subject of an application for authorization in the Member State concerned, that Member State shall forthwith request the authorities of the Member State which has granted the authorization to forward to it the assessment report referred to in Article 21(4). Within 90 days of the receipt of the assessment report, the Member State concerned shall either recognize the decision of the first Member State and the summary of the product characteristics as approved by it or, if it considers that there are grounds for supposing that the authorization of the medicinal product concerned may present a risk to public health, it shall apply the procedures set out in Articles 29 to 34.

Article 19

In order to examine the application submitted in accordance with Articles 8 and 10(1), the competent authority of the Member State:

1. must verify whether the particulars submitted in support of the application comply with the said Articles 8 and 10(1) and examine whether the conditions for issuing an authorization to place medicinal products on the market (marketing authorization) are complied with.

2. may submit the medicinal product, its starting materials and, if need be, its intermediate products or other constituent materials, for testing by a State laboratory or by a laboratory designated for that purpose in order to ensure that the control methods employed by the manufacturer and described in the particulars accompanying the application in accordance with Article 8(3)(h) are satisfactory.

3. may, where appropriate, require the applicant to supplement the particulars accompanying the application in respect of the items listed in the Articles 8(3) and 10(1). Where the competent authority avails itself of this option, the time limits laid down in Article 17 shall be suspended until such time as the supplementary information required has been provided. Likewise, these time limits shall be suspended for the time allowed the applicant, where appropriate, for giving oral or written explanation.

Article 20

Member States shall take all appropriate measures to ensure that:

(a) the competent authorities verify that manufacturers and importers of medicinal products coming from third countries are able to carry out manufacture in compliance with the particulars supplied pursuant to Article 8(3)(d), and/or to carry out controls according to the methods described in the particulars accompanying the application in accordance with Article 8(3)(h); 
(b) the competent authorities may allow manufacturers and importers of medicinal products coming from third countries, in exceptional and justifiable cases, to have certain stages of manufacture and/or certain of the controls referred to in (a) carried out by third parties; in such cases, the verifications by the competent authorities shall also be made in the establishment designated.

Article 21

1. When the marketing authorization is issued, the holder shall be informed, by the competent authorities of the Member State concerned, of the summary of the product characteristics as approved by it.

2. The competent authorities shall take all necessary measures to ensure that the information given in the summary is in conformity with that accepted when the marketing authorization is issued or subsequently.

3. The competent authorities shall forward to the Agency a copy of the authorization together with the summary of the product characteristics.

4. The competent authorities shall draw up an assessment report and comments on the dossier as regards the results of the analytical and pharmacotoxicological tests and the clinical trials of the medicinal product concerned. The assessment report shall be updated whenever new information becomes available which is of importance for the evaluation of the quality, safety or efficacy of the medicinal product concerned.

Article 22

In exceptional circumstances, and following consultation with the applicant, an authorization may be granted subject to certain specific obligations, including:

- the carrying out of further studies following the granting of authorization,

- the notification of adverse reactions to the medicinal product.

These exceptional decisions may be adopted only for objective and verifiable reasons and shall be based on one of the causes referred to in Part 4 (G) of Annex I.

L 311/78 EN Official Journal of the European Communities 28.11.2001

Article 23

After an authorization has been issued, the authorization holder must, in respect of the methods of manufacture and control provided for in Article 8(3)(d) and (h), take account of scientific and technical progress and introduce any changes that may be required to enable the medicinal product to be manufactured and checked by means of generally accepted scientific methods. These changes shall be subject to the approval of the competent authority of the Member State concerned.

Article 24

Authorization shall be valid for five years and shall be renewable for five-year periods, on application by the holder at least three months before the expiry date and after consideration by the competent authority of a dossier containing in particular details of the data on pharmacovigilance and other information relevant to the monitoring of the medicinal product.

Article 25 
Authorization shall not affect the civil and criminal liability of the manufacturer and, where applicable, of the marketing authorization holder.

Article 26

The marketing authorisation shall be refused if, after verification of the particulars and documents listed in Articles 8 and 10(1), it proves that:

(a) the medicinal product is harmful in the normal conditions of use, or

(b) that its therapeutic efficacy is lacking or is insufficiently substantiated by the applicant, or

(c) that its qualitative and quantitative composition is not as declared. Authorisation shall likewise be refused if the particulars and documents submitted in support of the application do not comply with Articles 8 and 10(1).

\section{CHAPTER 4}

Mutual recognition of authorizations

Article 27

1. In order to facilitate the adoption of common decisions by Member States on the authorization of medicinal products on the basis of the scientific criteria of quality, safety and efficacy, and to achieve thereby the free movement of medicinal products within the Community, a Committee for Proprietary Medicinal Products, hereinafter referred to as .the Committee., is hereby set up. The Committee shall be part of the Agency.

2. In addition to the other responsibilities conferred upon it by Community law, the Committee shall examine any question relating to the granting, variation, suspension or withdrawal of marketing authorization which is submitted to it in accordance with this Directive.

3. The Committee shall draw up its own Rules of Prodecure.

Article 28

1. Before submitting the application for recognition of a marketing authorization, the holder of the authorization shall inform the Member State which granted the authorization on which the application is based (hereinafter .reference Member State.), that an application is to be made in accordance with this Directive and shall notify it of any additions to the original dossier; that Member State may require the applicant to provide it with all the particulars and documents necessary to enable it to check that the dossiers filed are identical. In addition the holder of the authorization shall request the reference Member State to prepare an assessment report in respect of the medicinal product concerned, or, if necessary, to update any existing assessment report. That Member State shall prepare the assessment report, or update it, within 90 days of the receipt of the request. At the same time as the application is submitted in accordance with paragraph 2, the reference Member State shall forward the assessment report to the Member State or Member States concerned by the application.

2. In order to obtain the recognition according to the procedures laid down in this Chapter in one or more of the Member States of a marketing authorization issued by a Member State, the holder of the authorization shall submit an application to the 
competent authorities of the Member State or Member States concerned, together with the information and particulars referred to in Articles 8,10(1) and 11. He shall testify that the dossier is identical to that accepted by the reference Member State, or shall identify any additions or amendments it may contain. In the latter case, he shall certify that the summary of the product characteristics proposed by him in accordance with Article 11 is identical to that accepted by the reference Member State in accordance with Article 21. Moreover, he shall certify that all the dossiers filed as part of the procedure are identical.

3. The holder of the marketing authorization shall communicate the application to the Agency, inform it of the Member States concerned and of the dates of submission of the application and send it a copy of the authorization granted by the reference Member State. He shall also send the Agency copies of any such authorization which may have been granted by the other Member States in respect of the medicinal product concerned, and shall indicate whether any application for authorization is currently under consideration in any Member State.

28.11.2001 EN Official Journal of the European Communities L 311/79

4. Save in the exceptional case provided for in Article 29(1), each Member State shall recognize the marketing authorization granted by the reference Member State within 90 days of receipt of the application and the assessment report. It shall inform the reference Member State which granted the initial authorization, the other Member States concerned by the application, the Agency, and the marketing authorization holder.

Article 29

1. Where a Member State considers that there are grounds for supposing that the marketing authorization of the medicinal product concerned may present a risk to public health, it shall forthwith inform the applicant, the reference Member State which granted the initial authorization, any other Member States concerned by the application and the Agency. The Member State shall state its reasons in detail and shall indicate what action may be necessary to correct any defect in the application.

2. All the Member States concerned shall use their best endeavours to reach agreement on the action to be taken in respect of the application. They shall provide the applicant with the opportunity to make his point of view known orally or in writing. However, if the Member States have not reached agreement within the time limit referred to in Article 28(4) they shall forthwith refer the matter to the Agency with regard to the Committee's reference for the application of the procedure laid down in Article 32.

3. Within the time limit referred to in Article 28(4), the Member States concerned shall provide the Committee with a detailed statement of the matters on which they have been unable to reach agreement and the reasons for their disagreement. The applicant shall be provided with a copy of this information.

4. As soon as he is informed that the matter has been referred to the Committee, the applicant shall forthwith forward to the Committee a copy of the information and particulars referred to in Article 28(2). 
Article 30

If several applications submitted in accordance with Articles 8, 10(1) and Article 11 have been made for marketing authorization for a particular medicinal product, and Member States have adopted divergent decisions concerning the authorization of the medicinal product or its suspension or withdrawal, a Member State, or the Commission, or the marketing authorization holder may refer the matter to the Committee for application of the procedure laid down in

Article 32.

The Member State concerned, the marketing authorization holder or the Commission shall clearly identify the question which is referred to the Committee for consideration and, where appropriate, shall inform the holder. The Member State and the marketing authorization holder shall forward to the Committee all available information relating to the matter in question.

Article 31

The Member States or the Commission or the applicant or holder of the marketing authorization may, in specific cases where the interests of the Community are involved, refer the matter to the Committee for the application of the procedure laid down in Article 32 before reaching a decision on a request for a marketing authorization or on the suspension or withdrawal of an authorization, or on any other variation to the terms of a marketing authorization which appears necessary, in particular to take account of the information collected in accordance with Title IX. The Member State concerned or the Commission shall clearly identify the question which is referred to the Committee for consideration and shall inform the marketing authorization holder. The Member States and the marketing authorization holder shall forward to the Committee all available information relating to the matter in question.

Article 32

1. When reference is made to the procedure described in this Article, the Committee shall consider the matter concerned and issue a reasoned opinion within 90 days of the date on which the matter was referred to it. However, in cases submitted to the Committee in accordance with Articles 30 and 31, this period may be extended by 90 days. In case of urgency, on a proposal from its Chairman, the Committee may agree to a shorter deadline.

2. In order to consider the matter, the Committee may appoint one of its members to act as rapporteur. The Committee may also appoint individual experts to advise it on specific questions. When appointing experts, the Committee shall define their tasks and specify the time-limit for the completion of these tasks.

3. In the cases referred to in Articles 29 and 30, before issuing its opinion, the Committee shall provide the marketing authorization holder with an opportunity to present written or oral explanations. In the case referred to in Article 31, the marketing authorization holder may be asked to explain himself orally or in writing. If it considers it appropriate, the Committee may invite any other person to provide information relating to the matter before it. The Committee may suspend the time 
limit referred to in paragraph 1 in order to allow the marketing authorization holder to prepare explanations.

4. The Agency shall forthwith inform the marketing authorization holder where the opinion of the Committee is that:

L 311/80 EN Official Journal of the European Communities 28.11.2001

- the application does not satisfy the criteria for authorization, or

- the summary of the product characteristics proposed by the applicant in accordance with Article 11 should be amended, or

- the authorization should be granted subject to conditions, with regard to conditions considered essential for the safe and effective use of the medicinal product including pharmacovigilance, or

- a marketing authorization should be suspended, varied or withdrawn.

Within 15 days of the receipt of the opinion, the marketing authorization holder may notify the Agency in writing of his intention to appeal. In that case, he shall forward the detailed grounds for appeal to the Agency within 60 days of receipt of the opinion. Within 60 days of receipt of the grounds for appeal, the Committee shall consider whether its opinion should be revised, and the conclusions reached on the appeal shall be annexed to the assessment report referred to in paragraph 5 .

5. Within 30 days of its adoption, the Agency shall forward the final opinion of the Committee to the Member States, the Commission and the marketing authorization holder together with a report describing the assessment of the medicinal product and stating the reasons for its conclusions. In the event of an opinion in favour of granting or maintaining an authorization to place the medicinal product concerned on the market, the following documents shall be annexed to the opinion.

(a) a draft summary of the product characteristics, as referred to in Article 11;

(b) any conditions affecting the authorization within the meaning of paragraph 4 .

Article 33

Within 30 days of the receipt of the opinion, the Commission shall prepare a draft of the decision to be taken in respect of the application, taking into account Community law. In the event of a draft decision which envisages the granting of marketing authorization, the documents referred to in Article 32(5)(a) and (b) shall be annexed. Where, exceptionally, the draft decision is not in accordance with the opinion of the Agency, the Commission shall also annex a detailed explanation of the reasons for the differences. The draft decision shall be forwarded to the Member States and the applicant.

Article 34

1. A final decision on the application shall be adopted in accordance with the procedure referred to in Article 121(2).

2. The rules of procedure of the Standing Committee established by Article 121(1) shall be adjusted to take account of the tasks incumbent upon it in accordance with this Chapter.

These adjustments shall involve the following: 
- except in cases referred to in the third paragraph of Article 33, the opinion of the Standing Committee shall be obtained in writing,

- each Member State is allowed at least 28 days to forward written observations on the draft decision to the Commission,

- each Member State is able to require in writing that the draft decision be discussed by the Standing Committee, giving its reasons in detail.

Where, in the opinion of the Commission, the written observations of a Member State raise important new questions of a scientific or technical nature which have not been addressed in the opinion of the Agency, the Chairman shall suspend the procedure and refer the application back to the Agency for further consideration. The provisions necessary for the implementation of this paragraph shall be adopted by the Commission in accordance with the procedure referred to in Article 121(2).

3. A decision as referred to in paragraph 1 shall be addressed to the Member States concerned by the matter and reported to the marketing authorization holder. The Member States shall either grant or withdraw marketing authorization, or vary the terms of a marketing authorization as necessary to comply with the decision within 30 days of its notification. They shall inform the Commission and the Agency thereof.

Article 35

1. Any application by the marketing authorization holder to vary a marketing authorization which has been granted in accordance with the provisions of this Chapter shall be submitted to all the Member States which have previously authorized the medicinal product concerned. The Commission shall, in consultation with the Agency, adopt appropriate arrangements for the examination of variations to the terms of a marketing authorization. These arrangements shall include a notification system or administration procedures concerning minor variations and define precisely the concept of .a minor variation..

28.11.2001 EN Official Journal of the European Communities L 311/81

These arrangements shall be adopted by the Commission in the form of an implementing Regulation in accordance with the procedure referred to in Article 121(2).

2. In case of arbitration submitted to the Commission, the procedure laid down in Articles 32, 33 and 34 shall apply by analogy to variations made to marketing authorizations.

Article 36

1. Where a Member State considers that the variation of a marketing authorization which has been granted in accordance with the provisions of this Chapter or its suspension or withdrawal is necessary for the protection of public health, the Member State concerned shall forthwith refer the matter to the Agency for the application of the procedures laid down in Articles 32, 33 and 34.

2. Without prejudice to the provisions of Article 31, in exceptional cases, where urgent action is essential to protect public health, until a definitive decision is adopted a Member State may suspend the marketing and the use of the medicinal product concerned on its territory. It shall inform the Commission and the other Member States no later than the following working day of the reasons for its action. 
Article 37

Articles 35 and 36 shall apply by analogy to medicinal products authorized by Member States following an opinion of the Committee given in accordance with Article 4 of Directive 87/22/EEC before 1 January 1995.

Article 38

1. The Agency shall publish an annual report on the operation of the procedures laid down in this Chapter and shall forward that report to the European Parliament and the Council for information.

2. By 1 January 2001, the Commission shall publish a detailed review of the operation of the procedures laid down in this Chapter and shall propose any amendments which may be necessary to improve these procedures. The Council shall decide, under the conditions provided for in the Treaty, on the Commission proposal within one year of its submission.

Article 39

The provisions referred to in Articles 27 to 34 shall not apply to the homeopathic medicinal products referred to in Article 16(2).

\section{TITLE IV}

\section{MANUFACTURE AND IMPORTATION}

Article 40

1. Member States shall take all appropriate measures to ensure that the manufacture of the medicinal products within their territory is subject to the holding of an authorization. This manufacturing authorization shall be required nothwithstanding that the medicinal products manufactured are intended for export.

2. The authorization referred to in paragraph 1 shall be required for both total and partial manufacture, and for the various processes of dividing up, packaging or presentation. However, such authorization shall not be required for preparation, dividing up, changes in packaging or presentation where these processes are carried out, solely for retail supply, by pharmacists in dispensing pharmacies or by persons legally authorized in the Member States to carry out such processes.

3. Authorization referred to in paragraph 1 shall also be required for imports coming from third countries into a Member State; this Title and Article 118 shall have corresponding application to such imports as they have to manufacture.

Article 41

In order to obtain the manufacturing authorization, the applicant shall meet at least the following requirements:

(a) specify the medicinal products and pharmaceutical forms which are to be manufactured or imported and also the place where they are to be manufactured and/or controlled;

(b) have at his disposal, for the manufacture or import of the above, suitable and sufficient premises, technical equipment and control facilities complying with the legal requirements which the Member State concerned lays down as regards both manufacture and control and the storage of medicinal products, in accordance with Article 20; 
(c) have at his disposal the services of at least one qualified person within the meaning of Article 48. The applicant shall provide particulars in support of the above in his application.

Article 42

1. The competent authority of the Member State shall issue the manufacturing authorization only after having made sure of the accuracy of the particulars supplied pursuant to Article 41, by means of an inquiry carried out by its agents.

2. In order to ensure that the requirements referred to in Article 41 are complied with, authorization may be made conditional on the carrying out of certain obligations imposed either when authorization is granted or at a later date. L 311/82 EN Official Journal of the European Communities 28.11.2001

3 . The authorization shall apply only to the premises specified in the application and to the medicinal products and pharmaceutical forms specified in that same application.

Article 43

The Member States shall take all appropriate measures to ensure that the time taken for the procedure for granting the manufacturing authorization does not exceed 90 days from the day on which the competent authority receives the application.

Article 44

If the holder of the manufacturing authorization requests a change in any of the particulars referred to in points (a) and (b) of the first paragraph of Article 41, the time taken for the procedure relating to this request shall not exceed 30 days. In exceptional cases this period of time may be extended to 90 days.

\section{Article 45}

The competent authority of the Member State may require from the applicant further information concerning the particulars supplied pursuant to Article 41 and concerning the qualified person referred to in Article 48; where the competent authority concerned exercises this right, application of the time-limits referred to in Article 43 and 44 shall be suspended until the additional data required have been supplied.

Article 46

The holder of a manufacturing authorization shall at least be obliged:

(a) to have at his disposal the services of staff who comply with the legal requirements existing in the Member State concerned both as regards manufacture and controls;

(b) to dispose of the authorized medicinal products only in accordance with the legislation of the Member States concerned;

(c) to give prior notice to the competent authority of any changes he may wish to make to any of the particulars supplied pursuant to Article 41; the competent authority shall, in any event, be immediately informed if the qualified person referred to in Article 48 is replaced unexpectedly;

(d) to allow the agents of the competent authority of the Member State concerned access to his premises at any time; 
(e) to enable the qualified person referred to in Article 48 to carry out his duties, for example by placing at his disposal all the necessary facilities;

(f) to comply with the principles and guidelines of good manufacturing practice for medicinal products as laid down by Community law.

Article 47

The principles and guidelines of good manufacturing practices for medicinal products referred to in Article 46(f) shall be adopted in the form of a directive, in accordance with the procedure referred to in Article 121(2). Detailed guidelines in line with those principles will be published by the Commission and revised necessary to take account of technical and scientific progress.

Article 48

1. Member States shall take all appropriate measures to ensure that the holder of the manufacturing authorization has permanently and continuously at his disposal the services of at least one qualified person, in accordance with the conditions laid down in Article 49, responsible in particular for carrying out the duties specified in Article 51.

2. If he personally fulfils the conditions laid down in Article 49, the holder of the authorization may himself assume the responsibility referred to in paragraph 1.

Article 49

1. Member States shall ensure that the qualified person referred to in Article 48 fulfils the minimum conditions of qualification set out in paragraphs 2 and 3 .

2. A qualified person shall be in possession of a diploma, certificate or other evidence of formal qualifications awarded on completion of a university course of study, or a course recognized as equivalent by the Member State concerned, extending over a period of at least four years of theoretical and practical study in one of the following scientific disciplines: pharmacy, medicine, veterinary medicine, chemistry, pharmaceutical chemistry and technology, biology. However, the minimum duration of the university course may be three and a half years where the course is followed by a period of theoretical and practical training of a minimum duration of one year and including a training period of at least six months in a pharmacy open to the public, corroborated by an examination at university level. Where two university courses or two courses recognized by the State as equivalent co-exist in a Member State and where one of these extends over four years and the other over three years, the threeyear course leading to a diploma, certificate or other evidence of formal qualifications awarded on completion of a university course or its recognized equivalent shall be considered to fulfil the condition of duration referred to in the second subparagraph in so far as the diplomas, certificates or other evidence of formal qualifications awarded on completion of both courses are recognized as equivalent by the State in question.

The course shall include theoretical and practical study bearing upon at least the following basic subjects:

- Applied physics

- General and inorganic chemistry

28.11.2001 EN Official Journal of the European Communities L 311/83 
- Organic chemistry

- Analytical chemistry

- Pharmaceutical chemistry, including analysis of medicinal products

- General and applied biochemistry (medical)

- Physiology

- Microbiology

- Pharmacology

- Pharmaceutical technology

- Toxicology

- Pharmacognosy (study of the composition and effects of the natural active substances of plant and animal origin). Studies in these subjects should be so balanced as to enable the person concerned to fulfil the obligations specified in Article 51.

In so far as certain diplomas, certificates or other evidence of formal qualifications mentioned in the first subparagraph do not fulfil the criteria laid down in this paragraph, the competent authority of the Member State shall ensure that the person concerned provides evidence of adequate knowledge of the subjects involved.

3. The qualified person shall have acquired practical experience over at least two years, in one or more undertakings which are authorized to manufacture medicinal products, in the activities of qualitative analysis of medicinal products, of quantitative analysis of active substances and of the testing and checking necessary to ensure the quality of medicinal products. The duration of practical experience may be reduced by one year where a university course lasts for at least five years and by a year and a half where the course lasts for at least six years.

Article 50

1. A person engaging in the activities of the person referred to in Article 48 from the time of the application of Directive 75/319/EEC, in a Member State without complying with the provisions of Article 49 shall be eligible to continue to engage in those activities in the State concerned.

2. The holder of a diploma, certificate or other evidence of formal qualifications awarded on completion of a university course . or a course recognized as equivalent by the Member State concerned . in a scientific discipline allowing him to engage in the activities of the person referred to in Article 48 in accordance with the laws of that State may . if he began his course prior to 21 May 1975 . be considered as qualified to carry out in that State the duties of the person referred to in Article 48 provided that he has previously engaged in the following activities for at least two years before 21 May 1985 following notification of this directive in one or more undertakings authorized to manufacture: production supervision and/or qualitative and quantitative analysis of active substances, and the necessary testing and checking under the direct authority of the person referred to in Article 48 to ensure the quality of the medicinal products. If the person concerned has acquired the practical experience referred to in the first subparagraph before 21 May 1965, a further one year's practical 
experience in accordance with the conditions referred to in the first subparagraph will be required to be completed immediately before he engages in such activities.

Article 51

1. Member States shall take all appropriate measures to ensure that the qualified person referred to in Article 48, without prejudice to his relationship with the holder of the manufacturing authorization, is responsible, in the context of the procedures referred to in Article 52, for securing:

(a) in the case of medicinal products manufactured within the Member States concerned, that each batch of medicinal products has been manufactured and checked in compliance with the laws in force in that Member State and in accordance with the requirements of the marketing authorization;

(b) in the case of medicinal products coming from third countries, that each production batch has undergone in the importing Member State a full qualitative analysis, a quantitative analysis of at least all the active constituents and all the other tests or checks necessary to ensure the quality of medicinal products in accordance with the requirements of the marketing authorization. The batches of medicinal products which have undergone such controls in a Member State shall be exempt from the controls if they are marketed in another Member State, accompanied by the control reports signed by the qualified person.

2. In the case of medicinal products imported from a third country, where appropriate arrangements have been made by the Community with the exporting country to ensure that the manufacturer of the medicinal product applies standards of good manufacturing practice at least equivalent to those laid down by the Community, and to ensure that the controls referred to under point (b) of the first subparagraph of paragraph 1 have been carried out in the exporting country, the qualified person may be relieved of responsibility for carrying out those controls.

3. In all cases and particularly where the medicinal products are released for sale, the qualified person must certify in a register or equivalent document provided for that purpose, that each production batch satisfies the provisions of this Article; the said register or equivalent document must be kept L 311/84 EN Official Journal of the European Communities 28.11.2001 up to date as operations are carried out and must remain at the disposal of the agents of the competent authority for the period specified in the provisions of the Member State concerned and in any event for at least five years.

Article 52

Member States shall ensure that the duties of qualified persons referred to in Article 48 are fulfilled, either by means of appropriate administrative measures or by making such persons subject to a professional code of conduct. Member States may provide for the temporary suspension of such a person upon the commencement of administrative or disciplinary procedures against him for failure to fulfil his obligations.

Article 53

The provisions of this Title shall also apply to homeopathic medicinal products. 


\section{TITLE V}

\section{LABELLING AND PACKAGE LEAFLET}

\section{Article 54}

The following particulars shall appear on the outer packaging of medicinal products or, where there is no outer packaging, on the immediate packaging:

(a) the name of the medicinal product followed by the common name where the product contains only one active substance and if its name is an invented name; where a medicinal product is available in several pharmaceutical forms and/or several strengths, the pharmaceutical form and/or the strength (baby, child or adult as appropriate) must be included in the name of the medicinal product;

(b) a statement of the active substances expressed qualitatively and quantitatively per dosage unit or according to the form of administration for a given volume or weight, using their common names;

(c) the pharmaceutical form and the contents by weight, by volume or by number of doses of the product;

(d) a list of those excipients known to have a recognized action or effect and included in the guidelines published pursuant to Article 65. However, if the product is injectable, or a topical or eye preparation, all excipients must be stated;

(e) the method and, if necessary, the route of administration;

(f) a special warning that the medicinal product must be stored out of reach of children;

(g) a special warning, if this is necessary for the medicinal product;

(h) the expiry date in clear terms (month/year);

(i) special storage precautions, if any;

(j) special precautions for disposal of unused medicinal products or waste materials from medicinal products, if appropriate;

(k) the name and address of the holder of the authorization for placing the medicinal product on the market;

(l) the number of the authorization for placing the medicinal product on the market;

(m) the manufacturer's batch number;

(n) in the case of self-medication, instructions on the use of the medicinal products.

Article 55

1. The particulars laid down in Articles 54 and 62 shall appear on immediate packagings other than those referred to in paragraphs 2 and 3.

2. The following particulars at least shall appear on immediate packagings which take the form of blister packs and are placed in an outer packaging that complies with the requirements laid down in Articles 54 and 62.

- the name of the medicinal product as laid down in Article 54(a),

- the name of the holder of the authorization for placing the product on the market,

- the expiry date,

- the batch number.

3. The following particulars at least shall appear on small immediate packaging units on which the particulars laid down in Articles 54 and 62 cannot be displayed: 
- the name of the medicinal product and, if necessary, the strength and the route of administration,

- the method of administration,

- the expiry date,

- the batch number,

- the contents by weight, by volume or by unit.

Article 56

The particulars referred to in Articles 54, 55 and 62 shall be easily legible, clearly comprehensible and indelible. 28.11.2001 EN Official Journal of the European Communities L 311/85

Article 57

Notwithstanding Article 60, Member States may require the use of certain forms of labelling of the medicinal product making it possible to ascertain:

- the price of the medicinal product,

- the reimbursement conditions of social security organizations,

- the legal status for supply to the patient, in accordance with Title VI,

- identification and authenticity.

\section{Article 58}

The inclusion in the packaging of all medicinal products of a package leaflet shall be obligatory unless all the information required by Articles 59 and 62 is directly conveyed on the outer packaging or on the immediate packaging.

Article 59

1. The package leaflet shall be drawn up in accordance with the summary of the product characteristics; it shall include, in the following order:

(a) for the identification of the medicinal product:

- the name of the medicinal product, followed by the common name if the product contains only one active substance and if its name is an invented name; where a medicinal product is available in several pharmaceutical forms and/or several strengths, the pharmaceutical form and/or the strength (for example, baby, child, adult) must be included in the name of the medicinal product,

- a full statement of the active substances and excipients expressed qualitatively and a statement of the active substances expressed quantitatively, using their common names, in the case of each presentation of the medicinal product,

- the pharmaceutical form and the contents by weight, by volume or by number of doses of the product, in the case of each presentation of the product,

- the pharmaco-therapeutic group, or type of activity in terms easily comprehensible for the patient,

- the name and address of the holder of the authorization for placing the medicinal product on the market and of the manufacturer;

(b) the therapeutic indications;

(c) list of information which is necessary before taking the medicinal product: 
- contra-indications,

- appropriate precautions for use,

- forms of interaction with other medicinal products and other forms of interaction (e.g. alcohol, tobacco, foodstuffs) which may affect the action of the medicinal product,

- special warnings; this list must:

- take into account the particular condition of certain categories of users (e.g. children, pregnant or breastfeeding women, the elderly, persons with specific pathological conditions),

- mention, if appropriate, potential effects on the ability to drive vehicles or to operate machinery,

- detail those excipients, knowledge of which is important for the safe and effective use of the medicinal product and included in the guidelines published pursuant to Article 65;

(d) the necessary and usual instructions for proper use, in particular:

- the dosage,

- the method and, if necessary, route of administration,

- the frequency of administration, specifying if necessary, the appropriate time at which the medicinal product may or must be administered, and, as appropriate, depending on the nature of the product:

- the duration of treatment, where it should be limited,

- the action to be taken in the case of an overdose (e.g., symptoms, emergency procedures),

- the course of action to take when one or more doses have not been taken,

- indication, if necessary, of the risk of withdrawal effects;

(e) a description of the undesirable effects which can occur under normal use of the medicinal product and, if necessary, the action to be taken in such a case; the patient should be expressly invited to communicate any L 311/86 EN Official Journal of the European Communities 28.11.2001 undesirable effect which is not mentioned in the leaflet to his doctor or to his pharmacist;

(f) a reference to the expiry date indicated on the label, with:

- a warning against using the product after this date,

- where appropriate, special storage precautions,

- if necessary, a warning against certain visible signs of deterioration;

(g) the date on which the package leaflet was last revised.

2. Notwithstanding paragraph 1(b), the authority competent may decide that certain therapeutic indications shall not be mentioned in the package leaflet, where the dissemination of such information might have serious disadvantages for the patient.

Article 60 
Member States may not prohibit or impede the placing on the market of medicinal products within their territory on grounds connected with labelling or the package leaflet where these comply with the requirements of this Title.

Article 61

1. One or more specimens or mock-ups of the outer packaging and the immediate packaging of a medicinal product, together with the draft package leaflet, shall be submitted to the authorities competent for authorizing marketing when the marketing authorization is requested.

2. The competent authority shall refuse the marketing authorization if the labelling or the package leaflet do not comply with the provisions of this Title or if they are not in accordance with the particulars listed in the summary of product characteristics.

3. All proposed changes to an aspect of the labelling or the package leaflet covered by this Title and not connected with the summary of product characteristics shall be submitted to the authorities competent for authorizing marketing. If the competent authorities have not opposed a proposed change within 90 days following the introduction of the request, the applicant may put the change into effect.

4. The fact that the competent authority do not refuse a marketing authorization pursuant to paragraph 2 or a change to the labelling or the package leaflet pursuant to paragraph 3 does not alter the general legal liability of the manufacturer or as appropriate the marketing authorization holder.

Article 62

The outer packaging and the package leaflet may include symbols or pictograms designed to clarify certain information mentioned in Articles 54 and 59(1) and other information compatible with the summary of the product characteristics which is useful for health education, to the exclusion of any element of a promotional nature.

Article 63

1. The particulars for labelling listed in Articles 54, 59 and 62 shall appear in the official language or languages of the Member State where the product is placed on the market. The first subparagraph shall not prevent these particulars from being indicated in several languages, provided that the same particulars appear in all the languages used.

2. The package leaflet must be written in clear and understandable terms for the users and be clearly legible in the official language or languages of the Member State where the medicinal product is placed on the market. The first subparagraph shall not prevent the package leaflet being printed in several languages, provided that the same information is given in all the languages used.

3. The competent authorities may exempt labels and package leaflets for specific medicinal products from the obligation that certain particulars shall appear and that the leaflet must be in the official language or languages of the Member State where the product is placed on the market, when the product is not intended to be delivered to the patient for self-administration.

Article 64 
Where the provisions of this Title are not complied with, and a notice served on the person concerned has remained without effect, the competent authorities of the Member States may suspend the marketing authorization, until the labelling and the package leaflet of the medicinal product in question have been made to comply with the requirements of this Title.

Article 65 As necessary, the Commission shall publish guidelines concerning in particular:

- the formulation of certain special warnings for certain categories of medicinal products,

- the particular information needs relating to self-medication,

- the legibility of particulars on the labelling and package leaflet, 28.11.2001 EN Official Journal of the European Communities L 311/87

- methods for the identification and authentication of medicinal products,

- the list of excipients which must feature on the labelling of medicinal products and the way these excipients must be indicated. These guidelines shall be adopted in the form of a Directive, in accordance with the procedure referred to in Article 121(2).

Article 66

1. The outer carton and the container of medicinal products containing radionuclides shall be labelled in accordance with the regulations for the safe transport of radioactive materials laid down by the International Atomic Energy Agency. Moreover, the labelling shall comply with the provisions set out in paragraphs 2 and 3.

2. The label on the shielding shall include the particulars mentioned in Article 54. In addition, the labelling on the shielding shall explain in full, the codings used on the vial and shall indicate, where necessary, for a given time and date, the amount of radioactivity per dose or per vial and the number of capsules, or, for liquids, the number of millilitres in the container.

3. The vial shall be labelled with the following information:

- the name or code of the medicinal product, including the name or chemical symbol of the radionuclide,

- the batch identification and expiry date,

- the international symbol for radioactivity,

- the name of the manufacturer,

- the amount of radioactivity as specified in paragraph 2.

Article 67

The competent authority shall ensure that a detailed instruction leaflet is enclosed with the packaging of radiopharmaceuticals, radionuclide generators, radionuclide kits or radionuclide precursors. The text of this leaflet shall be established in accordance with the provisions of Article 59. In addition, the leaflet shall include any precautions to be taken by the user and the patient during the preparation and 
administration of the medicinal product and special precautions for the disposal of the packaging and its unused contents.

Article 68

Without prejudice to the provisions of Article 69, homeopathic medicinal products shall be labelled in accordance with the provisions of this title and shall be identified by a reference on their labels, in clear and legible form, to their homeopathic nature.

Article 69

1. In addition to the clear mention of the words

- homeopathic medicinal product., the labelling and, where appropriate, the package insert for the medicinal products referred to in Article 14(1) shall bear the following, and no other, information:

- the scientific name of the stock or stocks followed by the degree of dilution, making use of the symbols of the pharmacopoeia used in accordance with Article 1(5),

- name and address of the registration holder and, where appropriate, of the manufacturer,

- method of administration and, if necessary, route,

- expiry date, in clear terms (month, year),

- pharmaceutical form,

- contents of the sales presentation,

- special storage precautions, if any,

- a special warning if necessary for the medicinal product,

- manufacturer's batch number,

- registration number,

- homeopathic medicinal product without approved therapeutic indications.,

- a warning advising the user to consult a doctor if the symptoms persist during the use of the medicinal product.

2. Notwithstanding paragraph 1 , Member States may require the use of certain types of labelling in order to show:

- the price of the medicinal product,

- the conditions for refunds by social security bodies.

\section{TITLE VI}

\section{CLASSIFICATION OF MEDICINAL PRODUCTS}

Article 70

1. When a marketing authorization is granted, the competent authorities shall specify the classification of the medicinal product into:

- a medicinal product subject to medical prescription,

- a medicinal product not subject to medical prescription.

L 311/88 EN Official Journal of the European Communities 28.11.2001

To this end, the criteria laid down in Article 71(1) shall apply. 
2. The competent authorities may fix sub-categories for medicinal products which are available on medical prescription only. In that case, they shall refer to the following classification:

(a) medicinal products on renewable or non-renewable medical prescription;

(b) medicinal products subject to special medical prescription;

(c) medicinal products on restricted medical prescription, reserved for use in certain specialized areas.

Article 71

1. Medicinal products shall be subject to medical prescription where they:

- are likely to present a danger either directly or indirectly, even when used correctly, if utilized without medical supervision, or

- are frequently and to a very wide extent used incorrectly, and as a result are likely to present a direct or indirect danger to human health, or

- contain substances or preparations thereof, the activity and/or adverse reactions of which require further investigation, or

- are normally prescribed by a doctor to be administered parenterally.

2. Where Member States provide for the sub-category of medicinal products subject to special medical prescription, they shall take account of the following factors:

- the medicinal product contains, in a non-exempt quantity, a substance classified as a narcotic or a psychotropic substance within the meaning of the international conventions in force, such as the United Nations Conventions of 1961 and 1971, or

- the medicinal product is likely, if incorrectly used, to present a substantial risk of medicinal abuse, to lead to addiction or be misused for illegal purposes, or

- the medicinal product contains a substance which, by reason of its novelty or properties, could be considered as belonging to the group envisaged in the second indent as a precautionary measure.

3. Where Member States provide for the sub-category of medicinal products subject to restricted prescription, they shall take account of the following factors:

- the medicinal product, because of its pharmaceutical characteristics or novelty or in the interests of public health, is reserved for treatments which can only be followed in a hospital environment,

- the medicinal product is used in the treatment of conditions which must be diagnosed in a hospital environment or in institutions with adequate diagnostic facilities, although administration and follow-up may be carried out elsewhere, or

- the medicinal product is intended for outpatients but its use may produce very serious adverse reactions requiring a prescription drawn up as required by a specialist and special supervision throughout the treatment. 
4. A competent authority may waive application of paragraphs 1, 2 and 3 having regard to:

(a) the maximum single dose, the maximum daily dose, the strength, the pharmaceutical form, certain types of packaging; and/or

(b) other circumstances of use which it has specified.

5. If a competent authority does not designate medicinal products into subcategories referred to in Article 70(2), it shall nevertheless take into account the criteria referred to in paragraphs 2 and 3 of this Article in determining whether any medicinal product shall be classified as a prescription-only medicine.

Article 72

Medicinal products not subject to prescription shall be those which do not meet the criteria listed in Article 71.

Article 73

The competent authorities shall draw up a list of the medicinal products subject, on their territory, to medical prescription, specifying, if necessary, the category of classification. They shall update this list annually.

Article 74

On the occasion of the five-yearly renewal of the marketing authorization or when new facts are brought to their notice, the competent authorities shall examine and, as appropriate, amend the classification of a medicinal product, by applying the criteria listed in Article 71. 28.11.2001 EN Official Journal of the European Communities L $311 / 89$

Article 75

Each year, Member States shall communicate to the Commission and to the other Member States, the changes that have been made to the list referred to in Article 73.

TITLE VII

\section{WHOLESALE DISTRIBUTION OF MEDICINAL PRODUCTS}

Article 76

Without prejudice to Article 6, Member States shall take all appropriate action to ensure that only medicinal products in respect of which a marketing authorization has been granted in accordance with Community law are distributed on their territory.

Article 77

1. Member States shall take all appropriate measures to ensure that the wholesale distribution of medicinal products is subject to the possession of an authorization to engage in activity as a wholesaler in medicinal products, stating the place for which it is valid.

2. Where persons authorized or entitled to supply medicinal products to the public may also, under national law, engage in wholesale business, such persons shall be subject to the authorization provided for in paragraph 1.

3. Possession of a manufacturing authorization shall include authorization to distribute by wholesale the medicinal products covered by that authorization. Possession of an authorization to engage in activity as a wholesaler in medicinal products shall not give dispensation from the obligation to possess a manufacturing authorization and 
to comply with the conditions set out in that respect, even where the manufacturing or import business is secondary.

4. At the request of the Commission or any Member State, Member States shall supply all appropriate information concerning the individual authorizations which they have granted under paragraph 1 .

5. Checks on the persons authorized to engage in the activity of wholesaler in medicinal products and the inspection of their premises, shall be carried out under the responsibility of the Member State which granted the authorization.

6. The Member State which granted the authorization referred to in paragraph 1 shall suspend or revoke that authorization if the conditions of authorization cease to be met. It shall forthwith inform the other Member States and the Commission thereof.

7. Should a Member State consider that, in respect of a person holding an authorization granted by another Member State under the terms of paragraph 1, the conditions of authorization are not, or are no longer met, it shall forthwith inform the Commission and the other Member State involved. The latter shall take the measures necessary and shall inform the Commission and the first Member State of the decisions taken and the reasons for those decisions.

Article 78

Member States shall ensure that the time taken for the procedure for examining the application for the distribution authorization does not exceed 90 days from the day on which the competent authority of the Member State concerned receives the application. The competent authority may, if need be, require the applicant to supply all necessary information concerning the conditions of authorization. Where the authority exercises this option, the period laid down in the first paragraph shall be suspended until the requisite additional data have been supplied.

Article 79

In order to obtain the distribution authorization, applicants must fulfil the following minimum requirements: (a) they must have suitable and adequate premises, installations and equipment, so as to ensure proper conservation and distribution of the medicinal products; (b) they must have staff, and in particular, a qualified person designated as responsible, meeting the conditions provided for by the legislation of the Member State concerned; (c) they must undertake to fulfil the obligations incumbent on them under the terms of Article 80.

Article 80

Holders of the distribution authorization must fulfil the following minimum requirements:

(a) they must make the premises, installations and equipment referred to in Article 79(a) accessible at all times to the persons responsible for inspecting them;

(b) they must obtain their supplies of medicinal products only from persons who are themselves in possession of the distribution authorization or who are exempt from obtaining such authorization under the terms of Article 77(3); 
(c) they must supply medicinal products only to persons who are themselves in possession of the distribution authorization or who are authorized or entitled to supply medicinal products to the public in the Member State concerned;

L 311/90 EN Official Journal of the European Communities 28.11.2001

(d) they must have an emergency plan which ensures effective implementation of any recall from the market ordered by the competent authorities or carried out in cooperation with the manufacturer or marketing authorization holder for the medicinal product concerned;

(e) they must keep records either in the form of purchase/sales invoices, or on computer, or in any other form, giving for any transaction in medicinal products received or dispatched at least the following information:

- date,

- name of the medicinal product,

- quantity received or supplied,

- name and address of the supplier or consignee, as appropriate;

(f) they must keep the records referred to under (e) available to the competent authorities, for inspection purposes, for a period of five years;

(g) they must comply with the principles and guidelines of good distribution practice for medicinal products as laid down in Article 84.

Article 81

With regard to the supply of medicinal products to pharmacists and persons authorized or entitled to supply medicinal products to the public, Member States shall not impose upon the holder of a distribution authorization which has been granted by another Member State, any obligation, in particular public service obligations, more stringent than those they impose on persons whom they have themselves authorized to engage in equivalent activities. The said obligations should, moreover, be justified, in keeping with the Treaty, on grounds of public health protection and be proportionate in relation to the objective of such protection.

Article 82

For all supplies of medicinal products to a person authorized or entitled to supply medicinal products to the public in the Member State concerned, the authorized wholesaler must enclose a document that makes it possible to ascertain:

- the date,

- the name and pharmaceutical form of the medicinal product,

- the quantity supplied,

- the name and address of the supplier and consignor. Member States shall take all appropriate measures to ensure that persons authorized or entitled to supply medicinal products to the public are able to provide information that makes it possible to trace the distribution path of every medicinal product.

Article 83

The provisions of this Title shall not prevent the application of more stringent requirements laid down by Member States in respect of the wholesale distribution of: 
- narcotic or psychotropic substances within their territory,

- medicinal products derived from blood,

- immunological medicinal products,

- radiopharmaceuticals.

Article 84

The Commission shall publish guidelines on good distribution practice. To this end, it shall consult the Committee for Proprietary Medicinal Products and the Pharmaceutical Committee established by Council Decision 75/320/EEC (1).

Article 85

The provisions of this Title shall apply to homeopathic medicinal products, with the exception of those referred to in

Article 14(1).

TITLE VIII

ADVERTISING

Article 86

1. For the purposes of this Title, .advertising of medicinal products. shall include any form of door-to-door information, canvassing activity or inducement designed to promote the prescription, supply, sale or consumption of medicinal products; it shall include in particular:

- the advertising of medicinal products to the general public,

- advertising of medicinal products to persons qualified to prescribe or supply them,

- visits by medical sales representatives to persons qualified to prescribe medicinal products,

- the supply of samples,

28.11.2001 EN Official Journal of the European Communities L 311/91

- the provision of inducements to prescribe or supply medicinal products by the gift, offer or promise of any benefit or bonus, whether in money or in kind, except when their intrinsic value is minimal,

- sponsorship of promotional meetings attended by persons qualified to prescribe or supply medicinal products,

- sponsorship of scientific congresses attended by persons qualified to prescribe or supply medicinal products and in particular payment of their travelling and accommodation expenses in connection therewith.

2. The following are not covered by this Title:

- the labelling and the accompanying package leaflets, which are subject to the provisions of Title $\mathrm{V}$,

(1) OJ L 187, 9.6.1975, p. 23. 
- correspondence, possibly accompanied by material of a non-promotional nature, needed to answer a specific question about a particular medicinal product,

- factual, informative announcements and reference material relating, for example, to pack changes, adverse-reaction warnings as part of general drug precautions, trade catalogues and price lists, provided they include no product claims,

- statements relating to human health or diseases, provided there is no reference, even indirect, to medicinal products.

Article 87

1. Member States shall prohibit any advertising of a medicinal product in respect of which a marketing authorization has not been granted in accordance with Community law.

2. All parts of the advertising of a medicinal product must comply with the particulars listed in the summary of product characteristics.

3. The advertising of a medicinal product:

- shall encourage the rational use of the medicinal product, by presenting it objectively and without exaggerating its properties,

- shall not be misleading.

Article 88

1. Member States shall prohibit the advertising to the general public of medicinal products which:

- are available on medical prescription only, in accordance with Title VI,

- contain psychotropic or narcotic substances, such as the United Nations Conventions of 1961 and 1971,

- may not be advertised to the general public in accordance with the second subparagraph of paragraph 2.

2. Medicinal products may be advertised to the general public which, by virtue of their composition and purpose, are intended and designed for use without the intervention of a medical practitioner for diagnostic purposes or for the prescription or monitoring of treatment, with the advice of the pharmacist, if necessary. Member States shall prohibit the mentioning in advertising to the general public of therapeutic indications such as:

- tuberculosis,

- sexually transmitted diseases,

- other serious infectious diseases,

- cancer and other tumoral diseases,

- chronic insomnia,

- diabetes and other metabolic illnesses.

3. Member States shall be able to ban, on their territory, advertising to the general public of medicinal products the cost of which may be reimbursed. 
4. The prohibition referred to in paragraph 1 shall not apply to vaccination campaigns carried out by the industry and approved by the competent authorities of the Member States.

5. The prohibition referred to in paragraph 1 shall apply without prejudice to Article 14 of Directive 89/552/EEC.

6. Member States shall prohibit the direct distribution of medicinal products to the public by the industry for promotional purposes; they may, however, authorize such distribution in special cases for other purposes.

Article 89

1. Without prejudice to Article 88, all advertising to the general public of a medicinal product shall:

(a) be set out in such a way that it is clear that the message is an advertisement and that the product is clearly identified as a medicinal product;

(b) include the following minimum information:

- the name of the medicinal product, as well as the common name if the medicinal product contains only one active substance, L 311/92 EN Official Journal of the European Communities 28.11.2001

- the information necessary for correct use of the medicinal product,

- an express, legible invitation to read carefully the instructions on the package leaflet or on the outer packaging, as the case may be.

2. Member States may decide that the advertising of a medicinal product to the general public may, notwithstanding paragraph 1 , include only the name of the medicinal product if it is intended solely as a reminder.

Article 90

The advertising of a medicinal product to the general public shall not contain any material which:

(a) gives the impression that a medical consultation or surgical operation is unnecessary, in particular by offering a diagnosis or by suggesting treatment by mail;

(b) suggests that the effects of taking the medicine are guaranteed, are unaccompanied by adverse reactions or are better than, or equivalent to, those of another treatment or medicinal product;

(c) suggests that the health of the subject can be enhanced by taking the medicine;

(d) suggests that the health of the subject could be affected by not taking the medicine; this prohibition shall not apply to the vaccination campaigns referred to in Article 88(4);

(e) is directed exclusively or principally at children;

(f) refers to a recommendation by scientists, health professionals or persons who are neither of the foregoing but who, because of their celebrity, could encourage the consumption of medicinal products;

(g) suggests that the medicinal product is a foodstuff, cosmetic or other consumer product; 
(h) suggests that the safety or efficacy of the medicinal product is due to the fact that it is natural;

(i) could, by a description or detailed representation of a case history, lead to erroneous self-diagnosis;

(j) refers, in improper, alarming or misleading terms, to claims of recovery;

(k) uses, in improper, alarming or misleading terms, pictorial representations of changes in the human body caused by disease or injury, or of the action of a medicinal product on the human body or parts thereof;

(1) mentions that the medicinal product has been granted a marketing authorization.

Article 91

1. Any advertising of a medicinal product to persons qualified to prescribe or supply such products shall include:

- essential information compatible with the summary of product characteristics;

- the supply classification of the medicinal product. Member States may also require such advertising to include the selling price or indicative price of the various presentations and the conditions for reimbursement by social security bodies.

2. Member States may decide that the advertising of a medicinal product to persons qualified to prescribe or supply such products may, notwithstanding paragraph 1 , include only the name of the medicinal product, if it is intended solely as a reminder.

Article 92

1. Any documentation relating to a medicinal product which is transmitted as part of the promotion of that product to persons qualified to prescribe or supply it shall include, as a minimum, the particulars listed in Article 91(1) and shall state the date on which it was drawn up or last revised.

2. All the information contained in the documentation referred to in paragraph 1 shall be accurate, up-to-date, verifiable and sufficiently complete to enable the recipient to form his or her own opinion of the therapeutic value of the medicinal product concerned.

3. Quotations as well as tables and other illustrative matter taken from medical journals or other scientific works for use in the documentation referred to in paragraph 1 shall be faithfully reproduced and the precise sources indicated.

Article 93

1. Medical sales representatives shall be given adequate training by the firm which employs them and shall have sufficient scientific knowledge to be able to provide information which is precise and as complete as possible about the medicinal products which they promote.

28.11.2001 EN Official Journal of the European Communities L 311/93

2. During each visit, medical sales representatives shall give the persons visited, or have available for them, summaries of the product characteristics of each medicinal product they present together, if the legislation of the Member State so permits, with details of the price and conditions for reimbursement referred to in Article 91(1). 
3. Medical sales representatives shall transmit to the scientific service referred to in Article 98(1) any information about the use of the medicinal products they advertise, with particular reference to any adverse reactions reported to them by the persons they visit.

Article 94

1. Where medicinal products are being promoted to persons qualified to prescribe or supply them, no gifts, pecuniary advantages or benefits in kind may be supplied, offered or promised to such persons unless they are inexpensive and relevant to the practice of medicine or pharmacy.

2. Hospitality at sales promotion shall always be reasonable in level and secondary to the main purpose of the meeting and must not be extended to other than health professionals.

3. Persons qualified to prescribe or supply medicinal products shall not solicit or accept any inducement prohibited under paragraph 1 or contrary to paragraph 2 .

4. Existing measures or trade practices in Member States relating to prices, margins and discounts shall not be affected by paragraphs 1,2 and 3 .

Article 95

The provisions of Article 94(1) shall not prevent hospitality being offered, directly or indirectly, at events for purely professional and scientific purposes; such hospitality shall always be reasonable in level and remain subordinate to the main scientific objective of the meeting; it must not be extended to persons other than health professionals.

Article 96

1. Free samples shall be provided on an exceptional basis only to persons qualified to prescribe them and on the following conditions:

(a) the number of samples for each medicinal product each year on prescription shall be limited;

(b) any supply of samples shall be in response to a written request, signed and dated, from the prescribing agent;

(c) those supplying samples shall maintain an adequate system of control and accountability;

(d) each sample shall be identical with the smallest presentation on the market;

(e) each sample shall be marked free medical sample . not for sale. or shall show some other wording having the same meaning;

(f) each sample shall be accompanied by a copy of the summary of product characteristics;

(g) no samples of medicinal products containing psychotropic or narcotic substances within the meaning of international conventions, such as the United Nations Conventions of 1961 and 1971, may be supplied.

2. Member States may also place further restrictions on the distribution of samples of certain medicinal products.

Article 97 
1. Member States shall ensure that there are adequate and effective methods to monitor the advertising of medicinal products. Such methods, which may be based on a system of prior vetting, shall in any event include legal provisions under which persons or organizations regarded under national law as having a legitimate interest in prohibiting any advertisement inconsistent with this Title, may take legal action against such advertisement, or bring such advertisement before an administrative authority competent either to decide on complaints or to initiate appropriate legal proceedings.

2. Under the legal provisions referred to in paragraph 1, Member States shall confer upon the courts or administrative authorities powers enabling them, in cases where they deem such measures to be necessary, taking into account all the interests involved, and in particular the public interest:

- to order the cessation of, or to institute appropriate legal proceedings for an order for the cessation of, misleading advertising, or

- if misleading advertising has not yet been published but publication is imminent, to order the prohibition of, or to institute appropriate legal proceedings for an order for the prohibition of, such publication, even without proof of actual loss or damage or of intention or negligence on the part of the advertiser.

3. Member States shall make provision for the measures referred to in the second subparagraph to be taken under an accelerated procedure, either with interim effect or with definitive effect. L 311/94 EN Official Journal of the European Communities 28.11.2001 It shall be for each Member State to decide which of the two options set out in the first subparagraph to select.

4. Member States may confer upon the courts or administrative authorities powers enabling them, with a view to eliminating the continuing effects of misleading advertising the cessation of which has been ordered by a final decision:

- to require publication of that decision in full or in part and in such form as they deem adequate,

- to require in addition the publication of a corrective statement.

5. Paragraphs 1 to 4 shall not exclude the voluntary control of advertising of medicinal products by self-regulatory bodies and recourse to such bodies, if proceedings before such bodies are possible in addition to the judicial or administrative proceedings referred to in paragraph 1 .

Article 98

1. The marketing authorization holder shall establish, within his undertaking, a scientific service in charge of information about the medicinal products which he places on the market.

2. The marketing authorization holder shall:

- keep available for, or communicate to, the authorities or bodies responsible for monitoring advertising of medicinal products, a sample of all advertisements 
emanating from his undertaking together with a statement indicating the persons to whom it is addressed, the method of dissemination and the date of first dissemination,

- ensure that advertising of medicinal products by his undertaking conforms to the requirements of this Title,

- verify that medical sales representatives employed by his undertaking have been adequately trained and fulfill the obligations imposed upon them by Article 93(2) and (3),

- supply the authorities or bodies responsible for monitoring advertising of medicinal products with the information and assistance they require to carry out their responsibilities,

- ensure that the decisions taken by the authorities or bodies responsible for monitoring advertising of medicinal products are immediately and fully complied with.

\section{Article 99}

Member States shall take the appropriate measures to ensure that the provisions of this Title are applied and shall determine in particular what penalties shall be imposed should the provisions adopted in the execution of Title be infringed. Article 100 Advertising of the homeopathic medicinal products referred to in Article 13(2) and Article 14(1) shall be subject to the provisions of this Title with the exception of Article 87(1). However, only the information specified in Article 69(1) may be used in the advertising of such medicinal products. Moreover, each Member State may prohibit in its territory any advertising of the homeopathic medicinal products referred to in Article 13(2) and Article 14(1).

\section{TITLE IX}

\section{PHARMACOVIGILANCE}

Article 101

The Member States shall take all appropriate measures to encourage doctors and other health care professionals to report suspected adverse reactions to the competent authorities. The Member States may impose specific requirements on doctors and other health care professionals, in respect of the reporting of suspected serious or unexpected adverse reactions, in particular where such reporting is a condition of the marketing authorization.

Article 102

In order to ensure the adoption of appropriate regulatory decisions concerning the medicinal products authorized within the Community, having regard to information obtained about adverse reactions to medicinal products under normal conditions of use, the Member States shall establish a pharmacovigilance system. This system shall be used to collect information useful in the surveillance of medicinal products, with particular reference to adverse reactions in human beings, and to evaluate such information scientifically. Such information shall be collated with data on consumption of medicinal products. This system shall also take into account any 
available information on misuse and abuse of medicinal products which may have an impact on the evaluation of their benefits and risks.

Article 103

The marketing authorization holder shall have permanently and continuously at his disposal an appropriately qualified person responsible for pharmacovigilance. 28.11.2001 EN Official Journal of the European Communities L 311/95 That qualified person shall be responsible for the following:

(a) the establishment and maintenance of a system which ensures that information about all suspected adverse reactions which are reported to the personnel of the company, and to medical representatives, is collected and collated in order to be accessible at least at one point within the Community;

(b) the preparation for the competent authorities of the reports referred to in Article 104 , in such form as may be laid down by those authorities, in accordance with the guidance referred to in Article 106(1);

(c) ensuring that any request from the competent authorities for the provision of additional information necessary for the evaluation of the benefits and risks afforded by a medicinal product is answered fully and promptly, including the provision of information about the volume of sales or prescriptions of the medicinal product concerned;

(d) the provision to the competent authorities, of any other information relevant to the evaluation of the benefits and risks afforded by a medicinal product, including appropriate information on post-authorization safety studies.

Article 104

1. The marketing authorization holder shall be required to maintain detailed records of all suspected adverse reactions occurring either in the Community or in a third country.

2. The marketing authorization holder shall be required to record and to report all suspected serious adverse reactions which are brought to his attention by a health care professional immediately to the competent authority of the Member State in whose territory the incident occurred, and in no case later than 15 calendar days following the receipt of the information.

3. The marketing authorization holder shall be required to record and report all other suspected serious adverse reactions which meet the reporting criteria in accordance with the guidance referred to in Article 106(1) of which he can reasonably be expected to have knowledge immediately to the competent authority of the Member State in whose territory the incident occurred, and in no case later than 15 calendar days following the receipt of the information.

4. The marketing authorization holder shall ensure that all suspected serious and unexpected adverse reactions occurring in the territory of a third country and brought to his attention by a health care professional are reported immediately in accordance with the guidance referred to in Article 106(1), so that they are available to the Agency and to the competent authorities of the Member States where the medicinal 
product is authorised, and in no case later than 15 calendar days following the receipt of the information.

5. In the case of medicinal products which have been considered within the scope of Directive 87/22/EEC, or which have benefited from the procedures of mutual recognition foreseen in Articles 17 and 18 of this Directive, Article 28(4) of this Directive, and medicinal products for which there has been a referral to the procedures foreseen by Articles 32,33 and 34 of this Directive, the marketing authorisation holder shall additionally ensure that all suspected serious adverse reactions occurring in the Community are reported in the format and at intervals to be agreed with the reference Member State, or a competent authority acting as the reference Member State, in such a way so as to be accessible to the reference Member State.

6. Unless other requirements have been laid down as a condition of the granting of authorisation, or subsequently as indicated in the guidance referred to in Article 106(1), records of all adverse reactions shall be submitted to the competent authorities in the form of a periodic safety update report, either immediately upon request or periodically as follows: six monthly for the first two years after authorisation, annually for the subsequent two years, and at the time of the first renewal. Thereafter the periodic safety update reports shall be submitted at five-yearly intervals together with the application for renewal of the authorisation. The periodic safety update reports shall include a scientific evaluation of the benefit and risks afforded by the medicinal products.

7. Following the granting of a marketing authorisation, the marketing authorisation holder may request the amendment of the periods referred to in this article according to the procedure laid down by Commission Regulation (EC) No 541/95 (1).

Article 105

1. The Agency, in collaboration with the Member States and the Commission shall set up a data-processing network to facilitate the exchange of pharmacovigilance information regarding medicinal products marketed in the Community intended to allow all competent authorities to share the information at the same time.

2. Making use of the network foreseen in paragraph 1, Member States shall ensure that reports of suspected serious adverse reactions that have taken place on their territory are immediately made available to the Agency and the other Member States, and in any case within 15 calendar days of their notification, at the latest.

3. The Member States shall ensure that reports of suspected serious adverse reactions that have taken place on their territory are immediately made available to the marketing authorisation holder, and in any case within 15 calendar days of their notification, at the latest.

L 311/96 EN Official Journal of the European Communities 28.11.2001

Article 106

1. In order to facilitate the exchange of information about pharmacovigilance with-

(1) OJ L 55, 11.3.1995, p. 7. Regulation amended by Regulation (EC)

No $1146 / 98$ (OJ L 159, 3.6.1998, p. 31). 
in the Community, the Commission, in consultation with the Agency, Member States and interested parties, shall draw up guidance on the collection, verification and presentation of adverse reaction reports, including technical requirements for electronic exchange of pharmacovigilance information in accordance with internationally agreed formats and shall publish a reference to an internationally agreed medical terminology. This guidance shall be published in Volume 9 of The rules governing medicinal products in the European Community and shall take account of international harmonisation work carried out in the field of pharmacovigilance.

2. For the interpretation of the definitions referred to in Article 1 points 11 to 16 and the principles outlined in this Title, the marketing authorisation holder and the competent authorities shall refer to the guidance referred to in paragraph 1.

Article 107

1. Where, as a result of the evaluation of pharmacovigilance data, a Member State considers that a marketing authorisation should be suspended, withdrawn or varied in accordance with the guidance referred to in Article 106(1), it shall forthwith inform the Agency, the other Member States and the marketing authorisation holder.

2. In case of urgency, the Member State concerned may suspend the marketing authorisation of a medicinal product, provided the Agency, the Commission and the other Member States are informed at the latest on the following working day.

Article 108

Any amendments which may be necessary to update provisions of Articles 101 to 107 to take account of scientific and technical progress shall be adopted in accordance with the procedure referred to in Article 121(2).

TITLE X

SPECIAL PROVISIONS ON MEDICINAL PRODUCTS DERIVED

FROM HUMAN BLOOD AND PLASMA

Article 109

1. In respect of the use of human blood or human plasma as a starting material for the manufacture of medicinal products, Member States shall take the necessary measures to prevent the transmission of infectious diseases. In so far as this is covered by the amendments referred to in Article 121(1), as well as the application of the monographs of the European Pharmacopoeia regarding blood and plasma, these measures shall comprise those recommended by the Council of Europe and the World Health Organization, particularly with reference to the selection and testing of blood and plasma donors.

2. Member States shall take the necessary measures to ensure that human blood and human plasma donors and donation centres are always clearly identifiable.

3. All the safety guarantees referred to in paragraphs 1 and 2 must also be given by importers of human blood or human plasma from third countries.

Article 110

Member States shall take the necessary measures to promote Community selfsufficiency in human blood or human plasma. For this purpose, they shall encourage the voluntary unpaid donation of blood and plasma and shall take the necessary 
measures to develop the production and use of products derived from human blood or human plasma coming from voluntary unpaid donations. They shall notify the Commission of such measures.

\section{TITLE XI}

\section{SUPERVISION AND SANCTIONS}

Article 111

1. The competent authority of the Member State concerned shall ensure, by means of repeated inspections, that the legal requirements governing medicinal products are complied with. Such inspections shall be carried out by officials representing the competent authority who shall be empowered to:

(a) inspect manufacturing or commercial establishments and any laboratories entrusted by the holder of the manufacturing authorization with the task of carrying out checks pursuant to Article 20;

(b) take samples;

(c) examine any documents relating to the object of the inspection, subject to the provisions in force in the Member States on 21 May 1975 and which place restrictions on these powers with regard to the descriptions of the method of preparation.

2. Member States shall take all appropriate steps to ensure that the manufacturing processes used in the manufacture of immunological products are properly validated and attain batch-to-batch consistency.

3. After every inspection as referred to in paragraph 1 , the officials representing the competent authority shall report on whether the manufacturer complies with the principles and 28.11.2001 EN Official Journal of the European Communities L 311/97 guidelines of good manufacturing practice laid down in Article 47. The content of such reports shall be communicated to the manufacturer who has to undergo the inspection.

Article 112

Member States shall take all appropriate measures to ensure that the holder of the marketing authorization for a medicinal product and, where appropriate, the holder of the manufacturing authorization, furnish proof of the controls carried out on the medicinal product and/or the ingredients and of the controls carried out at an intermediate stage of the manufacturing process, in accordance with the methods laid down in Article 8(3)(h)

Article 113

For the purpose of implementing Article 112, Member States may require manufacturers of immunological products to submit to a competent authority copies of all the control reports signed by the qualified person in accordance with Article 51.

Article 114

1. Where it considers it necessary in the interests of public health, a Member State may require the holder of an authorization for marketing:

- live vaccines,

- immunological medicinal products used in the primary immunization of infants or of other groups at risk, 
- immunological medicinal products used in public health immunization programmes,

- new immunological medicinal products or immunological medicinal products manufactured using new or altered kinds of technology or new for a particular manufacturer, during a transitional period normally specified in the marketing authorization, to submit samples from each batch of the bulk and/or the medicinal product for examination by a State laboratory or a laboratory designated for that purpose before release on to the market unless, in the case of a batch manufactured in another Member State, the competent authority of that Member State has previously examined the batch in question and declared it to be in conformity with the approved specifications. Member States shall ensure that any such examination is completed within 60 days of the receipt of the samples.

2. Where, in the interests of public health, the laws of a Member State so provide, the competent authorities may require the marketing authorization holder for medicinal products derived from human blood or human plasma to submit samples from each batch of the bulk and/or the medicinal product for testing by a State laboratory or a laboratory designated for that purpose before being released into free circulation, unless the competent authorities of another Member State have previously examined the batch in question and declared it to be in conformity with the approved specifications. Member States shall ensure that any such examination is completed within 60 days of the receipt of the samples.

Article 115

Member States shall take all necessary measures to ensure that the manufacturing and purifying processes used in the preparation of medicinal products derived from human blood or human plasma are properly validated, attain batch-to-batch consistency and guarantee, insofar as the state of technology permits, the absence of specific viral contamination. To this end manufacturers shall notify the competent authorities of the method used to reduce or eliminate pathogenic viruses liable to be transmitted by medicinal products derived from human blood or human plasma. The competent authority may submit samples of the bulk and/or the medicinal product for testing by a State laboratory or a laboratory designated for that purpose, either during the examination of the application pursuant to Article 19, or after a marketing authorization has been granted.

Article 116

The competent authorities of the Member States shall suspend or revoke an authorization to place a medicinal product on the market where that product proves to be harmful in the normal conditions of use, or where its therapeutic efficacy is lacking, or where its qualitative and quantitative composition is not as declared. Therapeutic efficacy is lacking when it is established that therapeutic results cannot be obtained with the medicinal product. An authorization shall also be suspended or revoked where the particulars supporting the application as provided for in Articles 8, 10(1) and 11 are incorrect or have not been amended in accordance with Article 23, or where the controls referred to in Article 112 have not been carried out. 
Article 117

1. Notwithstanding the measures provided for in Article 116, Member States shall take all appropriate measures to ensure that the supply of the medicinal product shall be prohibited and the medicinal product withdrawn from the market if:

(a) the medicinal product proves to be harmful under normal conditions of use, or

(b) it is lacking in therapeutic efficacy, or

(c) its qualitative and quantitative composition is not as declared, or

L 311/98 EN Official Journal of the European Communities 28.11.2001

(d) the controls on the medicinal product and/or on the ingredients and the controls at an intermediate stage of the manufacturing process have not been carried out or if some other requirement or obligation relating to the grant of the manufacturing authorization has not been fulfilled.

2. The competent authority may limit the prohibition to supply the product, or its withdrawal from the market, to those batches which are the subject of dispute.

Article 118

1. The competent authority shall suspend or revoke the marketing authorization for a category of preparations or all preparations where any one of the requirements laid down in Article 41 is no longer met.

2. In addition to the measures specified in Article 117, the competent authority may suspend manufacture or imports of medicinal products coming from third countries, or suspend or revoke the manufacturing authorization for a category of preparations or all preparations where Articles 42, 46, 51 and 112 are not complied with.

Article 119

The provisions of this Title shall apply to homeopathic medicinal products, subject to the provisions of Article 14(3).

TITLE XII

STANDING COMMITTEE

Article 120

Any changes which are necessary in order to adapt Annex I to take account of scientific and technical progress shall be adopted in accordance with the procedure referred to in Article 121(2).

Article 121

1. The Commission shall be assisted by a Standing Committee on Medicinal Products for Human Use on the Adaptation to Technical Progress of the Directives on the Removal of Technical Barriers to Trade in the Medicinal Products Sector, (hereinafter referred to as the .Standing Committee.).

2. Where reference is made to this paragraph, Articles 5 and 7 of Decision 1999/468/EC shall apply, having regard to Article 8 thereof. The period provided for in Article 5(6) of Decision 1999/468/EC shall be set at three months. 3. The Standing Committee shall adopt its rules of procedure.

TITLE XIII

GENERAL PROVISIONS

Article 122 
Member States shall take all appropriate measures to ensure that the competent authorities concerned communicate to each other such information as is appropriate to guarantee that the requirements for the manufacturing authorizations or marketing authorizations are fulfilled. Upon reasoned request, Member States shall forthwith communicate the reports referred to in Article 111(3) to the competent authorities of another Member State. If, after considering the reports, the Member State receiving the reports considers that it cannot accept the conclusions reached by the competent authorities of the Member State in which the report was established, it shall inform the competent authorities concerned of its reasons and may request further information. The Member States concerned shall use their best endeavours to reach agreement. If necessary, in the case of serious differences of opinion, the Commission shall be informed by one of the Member States concerned.

Article 123

1. Each Member State shall take all the appropriate measures to ensure that decisions authorizing marketing, refusing or revoking a marketing authorization, cancelling a decision refusing or revoking a marketing authorization, prohibiting supply, or withdrawing a product from the market, together with the reasons on which such decisions are based, are brought to the attention of the Agency forthwith.

2. The marketing authorization holder shall be obliged to notify the Member States concerned forthwith of any action taken by him to suspend the marketing of a medicinal product or to withdraw a medicinal product from the market, together with the reasons for such action if the latter concerns the efficacy of the medicinal product or the protection of public health. Member States shall ensure that this information is brought to the attention of the Agency.

3. Member States shall ensure that appropriate information about action taken pursuant to paragraphs 1 and 2 which may affect the protection of public health in third countries is forthwith brought to the attention of the World Health Organization, with a copy to the Agency.

4. The Commission shall publish annually a list of the medicinal products which are prohibited in the Community. 28.11.2001 EN Official Journal of the European Communities L 311/99

\section{Article 124}

Member States shall communicate to each other all the information necessary to guarantee the quality and safety of homeopathic medicinal products manufactured and marketed within the Community, and in particular the information referred to in Articles 122 and 123.

Article 125

Every decision referred to in this Directive which is taken by the competent authority of a Member State shall state in detail the reasons on which it is based. Such decision shall be notified to the party concerned, together with information as to the redress available to him under the laws in force and of the time-limit allowed for access to such redress. Marketing authorizations, and decisions to revoke such 
authorizations, shall be published by each Member State in the appropriate official publication.

Article 126

An authorization to market a medicinal product shall not be refused, suspended or revoked except on the grounds set out in this Directive. No decision concerning suspension of manufacture or of importation of medicinal products coming from third countries, prohibition of supply or withdrawal from the market of a medicinal product may be taken except on the grounds set out in Articles 117 and 118.

Article 127

1. At the request of the manufacturer, the exporter or the authorities of an importing third country, Member States shall certify that a manufacturer of medicinal products is in possession of the manufacturing authorization. When issuing such certificates Member States shall comply with the following conditions:

(a) they shall have regard to the prevailing administrative arrangements of the World Health Organization;

(b) for medicinal products intended for export which are already authorized on their territory, they shall supply the summary of the product characteristics as approved in accordance with Article 21.

2. When the manufacturer is not in possession of a marketing authorization he shall provide the authorities responsible for establishing the certificate referred to in paragraph 1, with a declaration explaining why no marketing authorization is available.

\section{TITLE XIV}

\section{FINAL PROVISIONS}

Article 128

Directives 65/65/EEC, 75/318/EEC, 75/319/EEC, 89/342/EEC, 89/343/EEC, 89/381/EEC, 92/25/EEC, 92/26/EEC, 92/27/EEC, 92/28/EEC and 92/73/EEC, amended by the Directives referred to in Annex II, Part A, are repealed, without prejudice to the obligations of the Member States concerning the time-limits for implementation set out in Annex II, Part B. References to the repealed Directives shall be construed as references to this Directive and shall be read in accordance with the correlation table in Annex III.

Article 129

This Directive shall enter into force on the twentieth day following that of its publication in the Official Journal of the European Communities.

Article 130

This Directive is addressed to the Member States.

Done at Brussels, 6 November 2001.

For the European Parliament

The President

N. FONTAINE

For the Council

The President 


\section{REYNDERS}

L 311/100 EN Official Journal of the European Communities 28.11.2001

\section{ANNEX I}

ANALYTICAL, PHARMACOTOXICOLOGICAL AND CLINICAL STANDARDS AND PROTOCOLS IN

\section{RESPECT OF THE TESTING OF MEDICINAL PRODUCTS}

\section{INTRODUCTION}

The particulars and documents accompanying an application for marketing authorization pursuant to Articles 8 and

10(1) shall be presented in four parts, in accordance with the requirements set out in this Annex and taking account of the guidance published by the Commission in The rules governing medicinal products in the European Community, Volume II:

Notice to applicants for marketing authorizations for medicinal products for human use in the Member States of the European

Community.

In assembling the dossier for application for marketing authorization, applicants shall take into account the Community guidelines relating to the quality, safety and efficacy of medicinal products published by the Commission in The rules governing medicinal products in the European Community, Volume III and its supplements: Guidelines on the quality, safety and efficacy of medicinal products for human use.

All information which is relevant to the evaluation of the medicinal product concerned shall be included in the application, whether favourable or unfavourable to the product. In particular, all relevant details shall be given of any incomplete or abandoned pharmacotoxicological or clinical test or trial relating to the medicinal product. Moreover, in order to monitor the benefit/risk assessment after marketing authorization has been granted, any change to the data in the dossier, any new information not in the original application and all pharmacovigilance reports, shall be submitted to the competent authorities.

The general sections of this Annex give the requirements for all categories of medicinal products; they are supplemented by sections containing additional special requirements for radiopharmaceuticals and for biological medicinal products, such as immunological medicinal products derived from human blood or plasma. The additional special requirements for biological medicinal products are also applicable to medicinal products obtained through processes mentioned in Part A and the first indent of Part B of the Annex to Regulation (EEC) No 2309/93.

Member States shall also ensure that all tests on animals are conducted in accordance with Council Directive 86/609/EEC of 24 November 1986 on the approximation of laws, regulation and administrative provisions of the Member States regarding the protection of animals for experimental and other scientific purposes (1).

PART I

SUMMARY OF THE DOSSIER

A. Administrative data 
The medicinal product which is the subject of the application shall be identified by name and name of the active substance(s), together with the pharmaceutical form, the method of administration, the strength and the final presentation, including packaging.

The name and address of the applicant shall be given, together with the name and address of the manufacturers and the sites involved in the different stages of the manufacture (including the manufacturer of the finished product and the manufacturer(s) of the active substance(s)), and where relevant the name and address of the importer.

The applicant shall identify the number of volumes of documentation submitted in support of the application and indicate what samples, if any, are also provided.

Annexed to the administrative data shall be copies of the manufacturing authorization as defined in Article 40, together with a list of countries in which authorization has been granted, copies of all the summaries of product characteristics in accordance with Article 11 as approved by Member States and a list of countries in which an application has been submitted.

B. Summary of product characteristics

The applicant shall propose a summary of the product characteristics, in accordance with Article 11.

28.11.2001 EN Official Journal of the European Communities L 311/101

In addition the applicant shall provide samples or mock-ups of the packaging, labels and package leaflets for the medicinal product concerned.

C. Expert reports

In accordance with Article 12(2), expert reports must be provided on the chemical, pharmaceutical and biological documentation, the pharmacotoxicological documentation and the clinical documentation respectively.

The expert report shall consist of a critical evaluation of the quality of the medicinal product and the investigations carried out on animals and human beings and bring out all the data relevant for evaluation. It shall be worded so as to enable the reader to obtain a good understanding of the properties, quality, the proposed specifications and control methods, the safety, the efficacy, the advantages and disadvantages of the medicinal product.

All important data shall be summarized in an appendix to the expert report, whenever possible including report formats in tabular or in graphic form. The expert report and the summaries shall contain precise cross references to the information contained in the main documentation.

Each expert report shall be prepared by a suitably qualified and experienced person. It shall be signed and dated by the expert, and attached to the report shall be brief information about the educational background, training and professional experience of the expert. The professional relationship of the expert to the applicant shall be declared.

PART 2

(1) OJ L 358, 18.12.1986, p.1. 


\section{CHEMICAL, PHARMACEUTICAL AND BIOLOGICAL TESTING OF MED- ICINAL PRODUCTS}

All the test procedures shall correspond to the state of scientific progress at the time and shall be validated procedures;

results of the validation studies shall be provided.

All the test procedure(s) shall be described in sufficiently precise detail so as to be reproducible in control tests, carried out at the request of the competent authority; any special apparatus and equipment which may be used shall be described in adequate detail, possibly accompanied by a diagram. The formulae of the laboratory reagents shall be supplemented, if necessary, by the manufacturing method. In the case of test procedures included in the European Pharmacopoeia or the pharmacopoeia of a Member State, this description may be replaced by a detailed reference to the pharmacopoeia in question.

A. Qualitative and quantitative particulars of the constituents

The particulars and documents which must accompany applications for marketing authorization, pursuant to point 3 of Article 8(3)(c) shall be submitted in accordance with the following requirements.

1. Qualitative particulars

1.1. .Qualitative particulars. of all the constituents of the medicinal product shall mean the designation or description

of:

- the active substance(s),

- the constituent(s) of the excipients, whatever their nature or the quantity used, including colouring matter, preservatives, adjuvants, stabilizers, thickeners, emulsifiers, flavouring and aromatic substances, etc.,

- the constituents, intended to be ingested or otherwise administered to the patient, of the outer covering of the medicinal products . capsules, gelatine capsules, rectal capsules, etc.

These particulars shall be supplemented by any relevant data concerning the container and, where appropriate, its manner of closure, together with details of devices with which the medicinal product will be used or administered and which will be delivered with the medicinal product.

1.2. In the context of a radiopharmaceutical kit, which is to be radiolabelled after supply by the manufacturer, the active substance is considered to be that part of the formulation which is intended to carry or bind the radionuclide. Details of the source of the radionuclide shall be stated. In addition, any compounds essential for the radiolabelling shall be stated.

In a generator, both mother and daughter radionuclides are to be considered as active substances.

L 311/102 EN Official Journal of the European Communities 28.11.2001

2. The .usual terminology., to be used in describing the constituents of medicinal products, shall mean, notwithstanding the application of the other provisions in Article 8(3)(c): 
- in respect of substances which appear in the European Pharmacopoeia or, failing this, in the national pharmacopoeia of one of the Member States, the main title at the head of the monograph in question, with reference to the pharmacopoeia concerned,

- in respect of other substances, the international non-proprietary name recommended by the World Health Organization, which may be accompanied by another non-proprietary name, or, failing these, the exact scientific designation; substances not having an international non-proprietary name or an exact scientific designation shall be described by a statement of how and from what they were prepared, supplemented, where appropriate, by any other relevant details,

- in respect of colouring matter, designation by the .E. code assigned to them in Council Directive 78/25/EEC of 12 December 1977 on the approximation of the rules of the Member States concerning the colouring matters authorized for use in medicinal products (1).

3. Quantitative particulars

3.1. In order to give .quantitative particulars. of the active substances of the medicinal products, it is necessary, depending on the pharmaceutical form concerned, to specify the mass, or the number of units of biological activity, either per dosageunit or per unit of mass or volume, of each active substance. Units of biological activity shall be used for substances which cannot be defined chemically. Where an International Unit of biological activity has been defined by the World Health Organization, this shall be used.

Where no International Unit has been defined, the units of biological activity shall be expressed in such a way as to provide unambiguous information on the activity of the substances.

Whenever possible, biological activity per units of mass shall be indicated. This information shall be supplemented:

- in respect of injectable preparations, by the mass or units of biological activity of each active substance in the unit container, taking into account the usable volume of the product, after reconstitution, where appropriate,

- in respect of medicinal products to be administered by drops, by the mass or units of biological activity of each active substance contained in the number of drops corresponding to $1 \mathrm{ml}$ or $1 \mathrm{~g}$ of the preparation,

- in respect of syrups, emulsions, granular preparations and other pharmaceutical forms to be administered in measured quantities, by the mass or units of biological activity of each active substance per measured quantity.

3.2. Active substances present in the form of compounds or derivatives shall be designated quantitatively by their total mass, and if necessary or relevant, by the mass of the active entity or entities of the molecule.

3.3. For medicinal products containing an active substance which is the subject of an application for marketing authorization in any Member State for the first time, 
the quantitative statement of an active substance which is a salt or hydrate shall be systematically expressed in terms of the mass of the active entity or entities in the molecule. All subsequently authorized medicinal products in the Member States shall have their quantitative composition stated in the same way for the same active substance.

3.4. For allergen products, the quantitative particulars shall be expressed by units of biological activity, except for well defined allergen products for which the concentration may be expressed by mass/unit of volume.

3.5. The requirement to express the content of active substances in terms of the mass of active entities, as in point

3.3. above, may not apply to radiopharmaceuticals. For radionuclides, radioactivity shall be expressed in becquerels at a given date and, if necessary, time with reference to time zone. The type of radiation shall be indicated.

4. Development pharmaceutics

4.1. An explanation should be provided with regard to the choice of composition, constituents and container and the intended function of the excipients in the finished product. This explanation shall be supported by scientific data on development pharmaceutics. The overage during manufacture, with justification thereof, should be stated.

28.11.2001 EN Official Journal of the European Communities L 311/103

4.2. For radiopharmaceuticals, this should include a consideration of chemi$\mathrm{cal} /$ radiochemical purity and its relationship to biodistribution.

B. Description of manufacturing method

1. The description of the manufacturing method accompanying the application for marketing authorization pursuant to Article 8(3)(d), shall be drafted in such a way as to give an adequate synopsis of the nature of the operations employed.

For this purpose it shall include at least:

- mention of the various stages of manufacture, so that an assessment can be made of whether the processes employed in producing the pharmaceutical form might have produced an adverse change in the constituents,

- in the case of continuous manufacture, full details concerning precautions taken to ensure the homogeneity of the finished product,

- the actual manufacturing formula, with the quantitative particulars of all the substances used, the quantities of excipients, however, being given in approximate terms in so far as the pharmaceutical form makes this necessary; mention shall be made of any substances that may disappear in the course of manufacture; any overage shall be indicated and justified,

- a statement of the stages of manufacture at which sampling is carried out for in-process control tests, where other data in the documents supporting the application show such tests to be necessary for the quality control of the finished product,

(1) OJ L 11, 14.1.1978, p. 18. Directive as last amended by the 1985 Act of Accession. 
- experimental studies validating the manufacturing process, where a non-standard method of manufacture is used or where it is critical for the product,

- for sterile medicinal products, details of the sterilization processes and/or aseptic procedures used.

2. For radiopharmaceutical kits, the description of the manufacturing method shall also include details of the manufacture of the kit and details of its recommended final processing to produce the radioactive medicinal product.

For radionuclides, the nuclear reactions involved shall be discussed.

C. Controls of starting materials

1. For the purposes of this section, .starting materials. shall mean all the constituents of the medicinal product and, if necessary, of its container, as referred to in Section A, point 1 , above.

In the case of:

- an active substance not described in the European Pharmacopoeia or in the pharmacopoeia of a Member State,

or

- an active substance described in the European Pharmacopoeia or in the pharmacopoeia of a Member State

when prepared by a method liable to leave impurities not mentioned in the pharmacopoeial monograph and for which the monograph is inappropriate to adequately control its quality, which is manufactured by a person different from the applicant, the latter may arrange for the detailed description of the manufacturing method, quality control during manufacture and process validation to be supplied directly to the competent authorities by the manufacturer of the active substance. In this case, the manufacturer shall however provide the applicant with all the data which may be necessary for the latter to take responsibility for the medicinal product. The manufacturer shall confirm in writing to the applicant that he shall ensure batch to batch consistency and not modify the manufacturing process or specifications without informing the applicant. Documents and particulars supporting the application for such a change shall be supplied to the competent authorities.

The particulars and documents accompanying the application for marketing authorization pursuant to Article 8(3)(h) and (i) and 10(1), shall include the results of the tests, including batch analyses particularly for active substances, relating to quality control of all the constituents used. These shall be submitted in accordance with the following provisions.

1.1. Starting materials listed in pharmacopoeias

The monographs of the European Pharmacopoeia shall be applicable to all substances appearing in it.

In respect of other substances, each Member State may require observance of its own national pharmacopoeia with regard to products manufactured in its territory. 
L 311/104 EN Official Journal of the European Communities 28.11.2001

Constituents fulfilling the requirements of the European Pharmacopoeia or the pharmacopoeia of one of the Member States shall be deemed to comply sufficiently with Article 8(3)(h). In this case the description of the analytical methods may be replaced by a detailed reference to the pharmacopoeia in question.

However, where a starting material in the European Pharmacopoeia or in the pharmacopoeia of a Member State has been prepared by a method liable to leave impurities not controlled in the pharmacopoeia monograph, these impurities and their maximum tolerance limits must be declared and a suitable test procedure must be described.

Colouring matter shall, in all cases, satisfy the requirements of Directive 78/25/EEC.

The routine tests carried out on each batch of starting materials must be as stated in the application for marketing authorization. If tests other than those mentioned in the pharmacopoeia are used, proof must be supplied that the starting materials meet the quality requirements of that pharmacopoeia.

In cases where a specification contained in a monograph of the European Pharmacopoeia or in the national pharmacopoeia of a Member State might be insufficient to ensure the quality of the substance, the competent authorities may request more appropriate specifications from the marketing authorization holder.

The competent authorities shall inform the authorities responsible for the pharmacopoeia in question. The marketing authorization holder shall provide the authorities of that pharmacopoeia with the details of the alleged insufficiency and the additional specifications applied.

In cases where a starting material is described neither in the European Pharmacopoeia nor in the pharmacopoeia of a Member State, compliance with the monograph of a third country pharmacopoeia can be accepted; in such cases, the applicant shall submit a copy of the monograph accompanied where necessary by the validation of the test procedures contained in the monograph and by a translation where appropriate.

1.2. Starting materials not in a pharmacopoeia

Constituents which are not given in any pharmacopoeia shall be described in the form of a monograph under the following headings:

(a) the name of the substance, meeting the requirements of Section A, point 2, shall be supplemented by any trade or scientific synonyms;

(b) the definition of the substance, set down in a form similar to that used in the European Pharmacopoeia, shall be accompanied by any necessary explanatory evidence, especially concerning the molecular structure where appropriate; it must be accompanied by an appropriate description of the method of synthesis. Where substances can only be described by their manufacturing method, the description should be sufficiently detailed to characterize a substance which is constant both in its composition and in its effects; 
(c) methods of identification may be described in the form of complete techniques as used for production of the substance, and in the form of tests which ought to be carried out as a routine matter;

(d) purity tests shall be described in relation to the sum total of predictable impurities, especially those which may have a harmful effect, and, if necessary, those which, having regard to the combination of substances to which the application refers, might adversely affect the stability of the medicinal product or distort analytical results;

(e) with regard to complex substances of plant or animal/human origin, a distinction must be made between the case where multiple pharmacological effects render chemical, physical or biological control of the principal constituents necessary, and the case of substances containing one or more groups of principles having similar activity, in respect of which an overall method of assay may be accepted;

(f) when materials of animal/human origin are used, measures to ensure freedom from potentially pathogenic agents shall be described;

(g) for radionuclides, the nature of the radionuclide, the identity of the isotope, likely impurities, the carrier, the use and the specific activity shall be given;

(h) any special precautions that may be necessary during storage of the starting material and, if necessary, the maximum period of storage before retesting shall be given.

28.11.2001 EN Official Journal of the European Communities L 311/105

1.3. Physico-chemical characteristics liable to effect bio-availability

The following items of information concerning active substances, whether or not listed in the pharmacopoeias, shall be provided as part of the general description of the active substances if the bio-availability of the medicinal product depends on them:

- crystalline form and solubility coefficients,

- particle size, where appropriate after pulverization,

- state of solvation,

- oil/water coefficient of partition (1).

The first three indents are not applicable to substances used solely in solution.

2. For biological medicinal products, such as immunological medicinal products and medicinal products derived from human blood or plasma, the requirements of this paragraph shall apply. For the purposes of this paragraph, starting materials shall mean any substance used in the manufacture of the medicinal product; this includes the constituents of the medicinal product, and, if necessary, of its container, as referred to in paragraph $\mathrm{A}$, point 1 above, as well as source materials such as microorganisms, tissues of either plant or animal origin, cells or fluids (including blood) of human or animal origin, and biotechnological cell constructs. The origin and history of starting materials shall be described and documented.

The description of the starting material shall include the manufacturing strategy, purification/inactivation procedures with their validation and all in-process control 
procedures designed to ensure the quality, safety and batch to batch consistency of the finished product.

2.1. When cell banks are used, the cell characteristics shall be shown to have remained unchanged at the passage level used for the production and beyond.

2.2. Seed materials, cell banks, pools of serum or plasma and other materials of biological origin and, whenever possible, the source materials from which they are derived shall be tested for adventitious agents.

If the presence of potentially pathogenic adventitious agents is inevitable, the correspondant material shall be used only when further processing ensures their elimination and/or inactivation, and this shall be validated.

2.3. Whenever possible, vaccine production shall be based on a seed lot system and on established cell banks; for serums, defined pools of starting materials shall be used.

For bacterial and viral vaccines, the characteristics of the infectious agent shall be demonstrated on the seed. In addition, for live vaccines, the stability of the attenuation characteristics shall be demonstrated on the seed; if this proof is not sufficient, the attenuation characteristics shall also be demonstrated at the production stage.

2.4. For allergen products, the specifications and control methods for the source materials shall be described in as much detail as possible. The description shall include particulars concerning collection, pretreatment and storage.

2.5. For medicinal products derived from human blood or plasma, the origin and the criteria and procedures for collection, transportation and storage of the source material shall be described and documented.

Defined pools of source material shall be used.

3. For radiopharmaceuticals, starting materials include irradiation target materials.

D. Specific measures concerning the prevention of the transmission of animal spongiform encephalopathies The applicant must demonstrate that the medicinal product is manufactured in accordance with the Note for Guidance on Minimising the Risk of Transmitting Animal Spongiform Encephalopathy Agents via Medicinal Products and its updates, published by the Commission in Volume 3 of its publication The rules governing medicinal products in the European Community.

(1) The competent authorities may also request the $\mathrm{pK}$ and $\mathrm{pH}$ values if they think this information is essential.

L 311/106 EN Official Journal of the European Communities 28.11.2001

E. Control tests carried out at intermediate stages of the manufacturing process

1. The particulars and documents accompanying an application for marketing authorization, pursuant to Article 8(3)(h) and (i) and Article 10, paragraph 1 of this Directive, shall include particulars relating to the product control tests that may be carried out at an intermediate stage of the manufacturing process, with a view to ensuring the consistency of the technical characteristics and the production process.

These tests are essential for checking the conformity of the medicinal product with the formula when, exceptionally, an applicant proposes an analytical method for testing the finished product which does not include the assay of all the active 
substances (or of all the excipient constituents subject to the same requirements as the active substances).

The same applies where the quality control of the finished product depends on in-process control tests, particularly if the medicinal product is essentially defined by its method or preparation.

2. For biological medicinal products, such as immunological medicinal products and medicinal products derived from human blood or plasma, the procedures and the criteria of acceptability published as recommendations of the WHO (Requirements for Biological Substances) shall serve as guidelines for all controls of production stages which are not specified in the European Pharmacopoeia, or falling this, in the national pharmacopoeia of a Member State.

For inactivated or detoxified vaccines, effective inactivation or detoxification shall be verified during each production run, unless this control is dependent upon a test for which the availability of susceptible animals is limited. In this case, the test shall be carried out until consistency of production and correlation with appropriate in process controls have been established and thereafter compensated by appropriate in-process controls.

3. For modified or adsorbed allergen products, the products shall be qualitatively and quantitatively characterized at an intermediate stage, as late as possible in the manufacturing process.

F. Control tests on the finished product

1. For the control of the finished product, a batch of a medicinal product comprises all the units of a pharmaceutical form which are made from the same initial quantity of material and have undergone the same series of manufacturing and/or sterilization operations or, in the case of a continuous production process, all the units manufactured in a given period of time.

The application for marketing authorization shall list those tests which are carried out routinely on each batch of finished product. The frequency of the tests which are not carried out routinely shall be stated. Release limits shall be indicated.

The particulars and documents accompanying the application for marketing authorization pursuant to Article 8(3)(h) and (i) and Article 10(1) of this Directive, shall include particulars relating to control tests on the finished product at release. They shall be submitted in accordance with the following requirements.

The provisions of the monographs for pharmaceutical forms, immunosera, vaccines and radiopharmaceutical preparations of the European Pharmacopoeia or failing that, of a Member State, shall be applicable to all products defined therein. For all controls of biological medicinal products such as immunological medicinal products and medicinal products derived from human blood or plasma which are not specified in the European Pharmacopoeia or failing this, in the pharmacopoeia of a Member State, the procedures and the criteria of acceptability published as recommendations in the WHO (Requirements for Biological Substances) shall serve as guidelines.

If test procedures and limits other than those mentioned in the monographs of the European Pharmacopoeia, or failing this, in the national pharmacopoeia of a 
Member State, are used, proof shall be supplied that the finished product would, if tested in accordance with those monographs, meet the quality requirements of that pharmacopoeia for the pharmaceutical form concerned.

1.1. General characteristics of the finished product

Certain tests of the general characteristics of a product shall always be included among the tests on the finished product. These tests shall, wherever applicable, relate to the control of average masses and maximum deviations, to mechanical, physical or microbiological tests, organoleptic characteristics, physical characteristics such as density, $\mathrm{pH}$, refractive index, etc. For each of these characteristics, standards and tolerance limits shall be specified by the applicant in each particular case.

28.11.2001 EN Official Journal of the European Communities L 311/107

The conditions of the tests, where appropriate, the equipment/apparatus employed and the standards shall be described in precise details whenever they are not given in the European Pharmacopoeia or the pharmacopoeia of the Member States; the same shall apply in cases where the methods prescribed by such pharmacopoeias are not applicable.

Furthermore, solid pharmaceutical forms having to be administered orally shall be subjected to in vitro studies on the liberation and dissolution rate of the active substance or substances; these studies shall also be carried out where administration is by another means if the competent authorities of the Member State concerned consider this necessary.

1.2. Identification and assay of active substance (s)

Identification and assay of the active substance(s) shall be carried out either in an average representative sample from the production batch or in a number of dosageunits analysed individually.

Unless there is appropriate justification, the maximum acceptable deviation in the active substance content of the finished product shall not exceed $\pm 5 \%$ at the time of manufacture.

On the basis of the stability tests, the manufacturer must propose and justify maximum acceptable tolerance limits in the active substance content of the finished product up to the end of the proposed shelf-life.

In certain exceptional cases of particularly complex mixtures, where assay of active substances which are very numerous or present in very low amounts would necessitate an intricate investigation difficult to carry out in respect of each production batch, the assay of one or more active substances in the finished product may be omitted, on the express condition that such assays are made at intermediate stages in the production process. This relaxation may not be extended to the characterization of the substances concerned. This simplified technique shall be supplemented by a method of quantitative evaluation, enabling the competent authority to have the conformity of the medicinal product with its specification verified after it has been placed on the market.

An in vivo or in vitro biological assay shall be obligatory when physico-chemical methods cannot provide adequate information on the quality of the product. Such 
an assay shall, whenever possible, include reference materials and statistical analysis allowing calculation of confidence limits. Where these tests cannot be carried out on the finished product, they may be performed at an intermediate stage, as late as possible in the manufacturing process.

Where the particulars given in section $B$ show that a significant overage of an active substance is employed in the manufacture of the medicinal product, the description of the control tests on the finished product shall include, where appropriate, the chemical and, if necessary, the toxico-pharmacological investigation of the changes that this substance has undergone, and possibly the characterization and/or assay of the degradation products.

1.3. Identification and assay of excipient constituents

In so far as is necessary, the excipient(s) shall be subject at least to identification tests.

The test procedure proposed for identifying colouring matters must enable a verification to be made that such matters appear in the list annexed to Directive 78/25/EEC.

An upper and lower limit test shall be obligatory in respect of preserving agents and an upper limit test for any other excipient constituent liable to affect adversely organic functions; an upper and lower limit test shall be obligatory in respect of the excipient if it is liable to affect the bio-availability of an active substance, unless bio-availability is guaranteed by other appropriate tests.

1.4. Safety tests

1. Apart from the pharmacotoxicological tests submitted with the application for marketing authorization, particulars of safety tests, such as sterility, bacterial endotoxin, pyrogenicity and local tolerance in animals shall be included in the analytical particulars wherever such tests must be undertaken as a matter of routine in order to verify the quality of the product.

2. For all controls of biological medicinal products, such as immunological medicinal products and medicinal products derived from human blood or plasma, which are not specified in the European Pharmacopoeia, or failing this, in the national pharmacopoeia of a Member State, the procedures and the criteria of acceptability published as recommendations in the World Health Organization (Requirements for Biological Substances) shall serve as guidelines.

L 311/108 EN Official Journal of the European Communities 28.11.2001

3 . For radiopharmaceuticals, radionuclidic purity, radiochemical purity and specific activity shall be described. For content of radioactivity, the deviation from that stated on the label should not exceed $\pm 10 \%$.

For generators, details on the testing for mother and daughter radionuclides are required. For generator-eluates, tests for mother radionuclides and for other components of the generator system shall be provided.

For kits, the specifications of the finished product shall include tests on performance of products after radiolabelling. Appropriate controls on radiochemical and radionuclidic purity of the radiolabelled compound shall be included. Any material essential for radiolabelling shall be identified and assayed. 
G. Stability tests

1. The particulars and documents accompanying the application for marketing authorization pursuant to Article $8(3)(\mathrm{g})$ and $(\mathrm{h})$ shall be submitted in accordance with the following requirements.

A description shall be given of the investigations by which the shelf life, the recommended storage conditions and the specifications at the end of the shelf-life proposed by the applicant have been determined.

Where a finished product is liable to give rise to degradation products, the applicant must declare these and indicate characterization methods and test procedures.

The conclusions shall contain the results of analyses, justifying the proposed shelf life under the recommended storage conditions and the specifications of the finished product at the end of the shelf-life under these recommended storage conditions.

The maximum acceptable level of degradation products at the end of shelf-life shall be indicated.

A study of the interaction between product and container shall be submitted wherever the risk of such interaction is regarded as possible, especially where injectable preparations or aerosols for internal use are concerned.

2. Where for biological medicinal products, such as immunological medicinal products and medicinal products derived from human blood or plasma, stability tests cannot be carried out on the finished products, it is acceptable to carry out stability indicating tests at an intermediate stage of production as late as possible in the manufacturing process. In addition, there should be an evaluation of the stability of the finished product using other secondary tests.

3. For radiopharmaceuticals, information on stability shall be given for radionuclide generators, radionuclide kits and radiolabelled products. The stability during use of radiopharmaceuticals in multi-dose vials shall be documented.

PART 3

\section{TOXICOLOGICAL AND PHARMACOLOGICAL TESTS}

I. Introduction

1. The particulars and documents accompanying the application for marketing authorization pursuant to Articles

8(3)(i) and 10(1) shall be given in accordance with the requirements below.

Member States shall ensure that the safety tests are carried out in conformity with the provisions relating to good laboratory practice laid down by Council Directives 87/18/EEC (1) and 88/320/EEC (2).

The toxicological and pharmacological tests must show:

(a) the potential toxicity of the product and any dangerous or undesirable toxic effects that may occur under the proposed conditions of use in human beings; these should be evaluated in relation to the pathological condition concerned;

28.11.2001 EN Official Journal of the European Communities L 311/109

(1) OJ L $15,17.1 .1987$, p. 29.

(2) OJ L 145, 11.6.1988, p. 35. Directive as amended by Directive 90/18/EEC (OJ L 11, 13.1.1990, p. 37). 
(b) the pharmacological properties of the product, in both qualitative and quantitative relationship to the proposed use in human beings. All results must be reliable and of general applicability. Whenever appropriate, mathematical and statistical procedures shall be used in designing the experimental methods and in evaluating the results.

Additionally, it is necessary for clinicians to be given information about the therapeutic potential of the product.

2. Where a medicinal product is intended for topical use, systemic absorption must be investigated, due account also being taken of the possible use of the product on broken skin and absorption through other relevant surfaces.

Only if it is proved that systemic absorption under these conditions is negligible may repeated dose systemic toxicity tests, foetal toxicity tests and studies of reproductive function be omitted.

If, however, systemic absorption is demonstrated during therapeutic experimentation, toxicity tests shall be carried out on animals, including where necessary, foetal toxicity tests.

In all cases, tests of local tolerance after repeated application shall be carried out with particular care and include histological examinations; the possibility of sensitization shall be investigated and any carcinogenic potential investigated in the cases referred to in Section II E of this Part.

3. For biological medicinal products such as immunological medicinal products and medicinal products derived from human blood or plasma, the requirements of this Part may have to be adapted for individual products; therefore the testing programme carried out shall be justified by the applicant.

In establishing the testing programme, the following shall be taken into consideration:

- all tests requiring repeated administration of the product shall be designed to take account of the possible induction of, and interference by, antibodies;

- examination of reproductive function, of embryo/foetal and perinatal toxicity, of mutagenic potential and of carcinogenic potential shall be considered. Where components other than the active substance(s) are incriminated, validation of their removal may replace the study.

4. For radiopharmaceuticals, it is appreciated that toxicity may be associated with a radiation dose. In diagnosis, this is a consequence of the use of radiopharmaceuticals; in therapy, it is the wanted property. The evaluation of safety and efficacy of radiopharmaceuticals shall, therefore, address requirements for medicinal products and radiation dosimetry aspects. Organ/tissue exposure to radiation shall be documented. Absorbed radiation dose estimates shall be calculated according to a specified, internationally recognized system by a particular route of administration.

5. The toxicology and pharmacokinetics of an excipient used for the first time in the pharmaceutical field shall be investigated. 
6. Where there is a possibility of significant degradation during storage of the medicinal product, the toxicology of degradation products must be considered.

\section{PERFORMANCE OF TESTS}

A. Toxicity

1. Single dose toxicity

An acute test is a qualitative and quantitative study of the toxic reactions which may result from a single administration of the active substance or substances contained in the medicinal product, in the proportions and physico-chemical state in which they are present in the actual product.

The acute toxicity test must be carried out in two or more mammalian species of known strain unless a single species can be justified. At least two different routes of administration shall normally be used, one being identical with or similar to that proposed for use in human beings and the other ensuring systemic exposure to the substance.

This study will cover the signs observed, including local reactions. The period during which the test animals are observed shall be fixed by the investigator as being adequate to reveal tissue or organ damage or recovery, usually for a period of 14 days but not less than 7 days, but without exposing the animals to prolonged suffering.

L 311/110 EN Official Journal of the European Communities 28.11.2001

Animals dying during the observation period should be subject to autopsy as also should all animals surviving to the end of the observation period. Histopathological examinations should be considered on any organ showing macroscopic changes at autopsy. The maximum amount of information should be obtained from the animals used in the study.

The single dose toxicity tests should be conducted in such a way that signs of acute toxicity are revealed and the mode of death assessed as far as reasonably possible. In suitable species, a quantitative evaluation of the approximate lethal dose and information on the dose effect relationship should be obtained, but a high level of precision is not required.

These studies may give some indication of the likely effects of acute overdosage in man and may be useful for the design of toxicity studies requiring repeated dosing on the suitable animal species.

In the case of active substances in combination, the study must be carried out in such a way as to check whether or not there is enhancement of toxicity or if novel toxic effects occur.

2. Repeated dose toxicity (sub-acute or chronic toxicity)

Repeated dose toxicity tests are intended to reveal any physiological and/or anatomo-pathological changes induced by repeated administration of the active substance or combination of active substances under examination, and to determine how these changes are related to dosage.

Generally, it is desirable that two tests be performed: one short-term, lasting two to four weeks, the other long-term. The duration of the latter shall depend on 
the conditions of clinical use. Its purpose shall be to determine by experiment the non-toxic dose range of the product and normally it shall last three to six months.

In respect of medicinal products to be administered once only to humans, a single test lasting two to four weeks shall be performed.

If however, having regard to the proposed duration of use in human beings, the investigator sees fit to carry out experiments of greater or lesser duration than indicated above, he must give adequate reasons for doing so.

Reasons should also be given for the dosages chosen.

Repeated dose toxicity tests shall be carried out on two species of mammals one of which must be a non-rodent.

The choice of route(s) of administration employed shall depend on the intended therapeutic use and the possibilities of systemic absorption. The method and frequency of dosage shall be clearly stated.

The maximum dose should be chosen so as to bring harmful effects to light. The lower doses will then enable the animal's tolerance of the product to be determined.

Wherever possible, and always in experiments on small rodents, the design of the experiment and the control procedures must be suited to the scale of the problem being tackled and enable fiducial limits to be determined.

The evaluation of the toxic effects shall be based on observation of behaviour, growth, haematological and biochemical tests, especially those relating to the excretory mechanism, and also on autopsy reports and accompanying histological data. The choice and range of each group of tests will depend on the species of animal used and the state of scientific knowledge at the time.

In the case of new combinations of known substances that have been investigated in accordance with the provisions of this Directive, the chronic long-term tests may, except where acute and sub-acute toxicity tests have demonstrated potentiation or novel toxic effects, be suitably modified by the investigator who shall submit his reasons for such modification.

B. Examination of reproductive function

If the results of other tests reveal anything suggesting harmful effects on progeny or impairment of male or female reproductive function, this shall be investigated by appropriate tests.

28.11.2001 EN Official Journal of the European Communities L 311/111

C. Embryo/foetal and perinatal toxicity

This investigation comprises a demonstration of the toxic and especially the teratogenic effects observed in the issue of conception when the medicinal product under investigation has been administered to the female during pregnancy.

Although up to the present these tests have had only a limited predictive value in regard to the application of the results to human beings, they are thought to provide important information where the results show effects such as resorptions and other anomalies.

Omission of these tests, either because the medicinal product will not normally be used by women capable of child-bearing or for other reasons, must be adequately justified. 
Embryo/foetal toxicity studies shall normally be conducted on two mammalian species, one of which should be other than a rodent. Peri- and postnatal studies shall be conducted in at least one species. Where metabolism of a medicinal product in a particular species is known to be similar to that in man, it is desirable to include this species. Also, it is desirable that one of the species is the same as in the repeated dose toxicity studies.

The details of the test (number of animals, amounts administered, timing of administration and criteria for evaluation of results) shall depend on the state of scientific knowledge at the time when the application is lodged, and the level of statistical significance that the results must attain.

D. Mutagenic potential

The purpose of the study of mutagenic potential is to reveal the changes which a substance may cause in the genetic material of individuals or cells and which have the effect of making successors permanently and hereditarily different from their predecessors. This study is obligatory for any new substance.

The number and types of results and the criteria for their evaluation shall depend on the state of scientific knowledge at the time when the application is lodged.

E. Carcinogenic potential

Tests to reveal carcinogenic effects shall normally be required:

(a) in respect of substances having a close chemical analogy with known carcinogenic or cocarcinogenic compounds;

(b) in respect of substances which have given rise to suspicious changes during the long-term toxicological tests;

(c) in respect of substances which have given rise to suspicious results in the mutagenic-potential tests or in other short-term carcinogenicity tests.

Such tests may also be required in respect of substances to be included in medicinal products likely to be administered regularly over a prolonged period of a patient's life.

The state of scientific knowledge at the time when the application is lodged shall be taken into account when determining the details of the tests.

F. Pharmacodynamics

This heading covers the variations caused by the medicinal product in the functions of the physiological systems, whether these functions are normal or experimentally modified.

This study shall follow two distinct lines of approach.

Firstly, the actions on which the recommended application in therapeutic practice is based shall be adequately described. The results shall be expressed in quantitative terms using, (e.g. dose-effect curves, time-effect curves etc.), and wherever possible, compared with data relating to a substance whose activity is known. Where a higher therapeutic potency is being claimed for a substance, the difference shall be demonstrated and shown to be statistically significant.

Secondly, the investigator shall provide a general pharmacological characterization of the substance, with special reference to adverse reactions. In general, the main functions of the physiological systems should be investigated. 
The depth of this investigation must be increased as the doses liable to produce adverse reactions approach those producing the main effect for which the substance is being proposed.

L 311/112 EN Official Journal of the European Communities 28.11.2001

The experimental techniques, unless they are standard procedures, must be described in such detail as to allow them to be reproduced, and the investigator must establish their validity. The experimental results shall be set out clearly and, when relevant to the test, their statistical significance quoted.

Unless good reasons are given to the contrary, any quantitative modification of responses resulting from repeated administration of the substance shall be investigated.

Tests on combinations of active substances may be prompted either by pharmacological premisses or by indications of therapeutic effect.

In the first case, the pharmacodynamic study shall demonstrate those interactions which might make the combination of value in therapeutic use.

In the second case, where scientific justification for the combination is sought through therapeutic experimentation, the investigation shall determine whether the effects expected from the combination can be demonstrated in animals, and the importance of any collateral effects shall at least be investigated.

If a combination includes a novel active substance, the latter must previously have been studied in depth.

G. Pharmacokinetics

Pharmacokinetics means the study of the fate of the active substance within the organism, and covers the study of the absorption, distribution, biotransformation and excretion of the substance.

The study of these different phases may be carried out both by means of physical, chemical or biological methods, and by observation of the actual pharmacodynamic activity of the substance itself.

Information on distribution and elimination (i.e. biotransformation and excretion) shall be necessary in all cases where such data are indispensable to determine the dosage for humans, and in respect of chemotherapeutic substances (antibiotics, etc.) and substances whose use depends on their non-pharmacodynamic effects (e.g. numerous diagnostic agents, etc.).

Pharmacokinetic investigation of pharmacologically active substances is necessary.

In the case of new combinations of known substances which have been investigated in accordance with the provisions of this Directive, pharmacokinetic studies may not be required, if the toxicity tests and therapeutic experimentation justify their omission.

H. Local tolerance

The purpose of local tolerance studies is to ascertain whether medicinal products (both active substances and excipients) are tolerated at sites in the body which may come into contact with the medicinal product as a result of its administration in clinical use. The testing strategy shall be such that any mechanical effects of administration or purely physico-chemical actions of the product can be distinguished from toxicological or pharmacodynamic ones. 
I. Well-established medicinal use

For the purpose of demonstrating, pursuant to Article 10(1)(a)(ii), that the component(s) of a medicinal product have a well established use, with an acceptable level of safety, the following specific rules shall apply:

(a) Factors which have to be taken into account in order to establish a .well established medicinal use. of components of medicinal products are the time over which a substance has been used, quantitative aspects of the use of the substance, the degree of scientific interest in the use of the substance (reflected in the published scientific literature) and the coherence of scientific assessments. Therefore different periods of time may be necessary for establishing .well established use. of different substances. In any case, however, the period of time required for establishing a .well established medicinal use. of a component of a medicinal product must not be less than one decade from the first systematic and documented use of that substance as a medicinal product in the Community.

28.11.2001 EN Official Journal of the European Communities L 311/113

(b) The documentation submitted by the applicant should cover all aspects of the safety assessment and must include or refer to a review of the relevant literature, taking into account pre- and postmarketing studies and published scientific literature concerning experience in the form of epidemiological studies and in particular of comparative epidemiological studies. All documentation, both favourable and unfavourable, should be communicated.

(c) Particular attention must be paid to any missing information and justification must be given why demonstration of an acceptable level of safety can be supported although some studies are lacking.

(d) The Expert report must explain the relevance of any data submitted which concern a product different from the product intended for marketing. A judgment must be made whether the product studied can be considered as similar to the product which will be granted a marketing authorisation in spite of the existing differences.

(e) Post-marketing experience with other products containing the same components is of particular importance and applicants should put a special emphasis on this issue.

PART 4

\section{CLINICAL DOCUMENTATION}

The particulars and documents accompanying applications for marketing authorizations pursuant to Articles 8(3)(i) and 10(1) of this Directive shall be submitted in accordance with the provisions below.

A clinical trial is any systematic study of medicinal products in human subjects whether in patients or non-patient volunteers in order to discover or verify the effects of and/or identify any adverse reaction to investigational products, and/or study their absorption, distribution, metabolism and excretion in order to ascertain the efficacy and safety of the products.

Evaluation of the application for marketing authorization shall be based on clinical trials including clinical pharmacological trials designed to determine the efficacy and safety of the product under normal conditions of use, having regard to the therapeutic 
indications for use in human beings. Therapeutic advantages must outweigh potential risks.

A. General requirements

The clinical particulars to be provided pursuant to Articles 8(3)(i) and 10(1) must enable a sufficiently well-founded and scientifically valid opinion to be formed as to whether the medicinal product satisfies the criteria governing the granting of a marketing authorization. Consequently, an essential requirement is that the results of all clinical trials should be communicated, both favourable and unfavourable.

Clinical trials must always be preceded by adequate pharmacological and toxicological tests, carried out on animals in accordance with the requirements of Part 3 of this Annex. The investigator must acquaint himself with the conclusions drawn from the pharmacological and toxicological studies and hence the applicant must provide him at least with the investigator's brochure, consisting of all the relevant information known prior to the onset of a clinical trial including chemical, pharmaceutical and biological data, toxicological, pharmacokinetic and pharmacodynamic data in animals and the results of earlier clinical trials, with adequate data to justify the nature, scale and duration of the proposed trial; the complete pharmacological and toxicological reports shall be provided on request. For materials of human or animal origin, all available means shall be employed to ensure safety from transmission of infectious agents prior to the commencement of the trial.

B. Conduct of trials

1. Good clinical practice

1.1. All phases of clinical investigation, including bioavailability and bioequivalence studies, shall be designed, implemented and reported in accordance with good clinical practice.

1.2. All clinical trials shall be carried out in accordance with the ethical principles laid down in the current revision of the Declaration of Helsinki. In principle, the freely given informed consent of each trial subject shall be obtained and documented.

L 311/114 EN Official Journal of the European Communities 28.11.2001

The trial protocol (including statistical design), the technical application and documentation shall be submitted by the sponsor and/or investigator for an opinion to the relevant ethics committee. The trials shall not begin before the opinion of this committee has been received in writing.

1.3. Pre-established, systematic written procedures for the organization, conduct, data collection, documentation and verification of clinical trials shall be required.

1.4. In the case of radiopharmaceuticals, clinical trials shall be carried out under the responsibility of a medical doctor authorized to use radionuclides for medical purposes.

2. Archiving

The marketing authorization holder shall make arrangements for archiving of documentation.

(a) The investigator shall arrange for the retention of the patient identification codes for at least 15 years after the completion or discontinuation of the trial. 
(b) Patient files and other source data shall be kept for the maximum period of time permitted by the hospital, institution or private practice.

(c) The sponsor or other owner of the data shall retain all other documentation pertaining to the trial as long as the product is authorized. These procedures shall include:

- the protocol including the rationale, objectives and statistical design and methodology of the trial, with conditions under which it is performed and managed, and details of the investigational product, the reference medicinal product and/or the placebo used,

- standard operating procedures,

- all written opinions on the protocol and procedures,

- the investigator's brochure,

- case report forms on each trial subject,

- final report,

- audit certificate(s), if available.

(d) The final report shall be retained by the sponsor or subsequent owner, for five years after the medicinal product is no longer authorized.

Any change of ownership of the data shall be documented.

All data and documents shall be made available if requested by relevant authorities.

C. Presentation of results

1. The particulars of each clinical trial must contain sufficient detail to allow an objective judgement to be made:

- the protocol, including the rationale, objectives and statistical design and methodology of the trial, with conditions under which it is performed and managed, and details of the investigational medicinal product used,

- audit certificate(s), if available,

- the list of investigator(s), and each investigator shall give his name, address, appointments, qualifications and clinical duties, state where the trial was carried out and assemble the information in respect of each patient individually, including case report forms on each trial subject,

- final report signed by the investigator and for multicentre trials, by all the investigators or the coordinating (principal) investigator.

2. The particulars of clinical trials referred to above shall be forwarded to the competent authorities. However, in agreement with the competent authorities, the applicant may omit part of this information. Complete documentation shall be provided forthwith upon request.

28.11.2001 EN Official Journal of the European Communities L 311/115

3. The clinical observations shall be summarized for each trial indicating:

(a) the number and sex of patients treated;

(b) the selection and age-distribution of the groups of patients being investigated and the comparative tests; 
(c) the number of patients withdrawn prematurely from the trials and the reasons for such withdrawal;

(d) where controlled trials were carried out under the above conditions, whether the control group:

- received no treatment,

- received a placebo,

- received another medicinal product of known effect,

- received treatment other than therapy using medicinal products;

(e) the frequency of observed adverse reactions;

(f) details concerning patients who may be at increased risk, e.g. elderly people, children, women during pregnancy or menstruation, or whose physiological or pathological condition requires special consideration;

(g) parameters or evaluation criteria of efficacy and the results in terms of these parameters;

(h) a statistical evaluation of the results when this is called for by the design of the trials and the variable factors involved.

4. The investigator shall, in his conclusions on the experimental evidence, express an opinion on the safety of the product under normal conditions of use, its tolerance, its efficacy and any useful information relating to indications and contra-indications, dosage and average duration of treatment as well as any special precautions to be taken during treatment and the clinical symptoms of overdosage. In reporting the results of a multi-centre study, the principal investigator shall, in his conclusions, express an opinion on the safety and efficacy of the investigational medicinal product on behalf of all centres.

5. In addition, the investigator shall always indicate his observations on:

(a) any signs of habituation, addiction or difficulty in weaning patients from the medicinal product;

(b) any interactions that have been observed with other medicinal products administered concomitantly;

(c) the criteria determining exclusion of certain patients from the trials;

(d) any deaths which occurred during the trial or within the follow-up period.

6. Particulars concerning a new combination of medicinal substances must be identical to those required for new medicinal products and must substantiate the safety and efficacy of the combination.

7. Total or partial omission of data must be explained. Should unexpected results occur during the course of the trials, further preclinical toxicological and pharmacological tests must be undertaken and reviewed.

If the medicinal product is intended for long-term administration, particulars shall be given of any modification of the pharmacological action following repeated administration, as well as the establishment of long-term dosage.

D. Clinical pharmacology

1. Pharmacodynamics 
The pharmacodynamic action correlated to the efficacy shall be demonstrated including:

- the dose-response relationship and its time course,

- justification for the dosage and conditions of administration,

- the mode of action, if possible.

L 311/116 EN Official Journal of the European Communities 28.11.2001

The pharmacodynamic action not related to efficacy shall be described.

The demonstration of pharmacodynamic effects in human beings shall not in itself be sufficient to justify conclusions regarding any particular potential therapeutic effect.

2. Pharmacokinetics

The following pharmacokinetic characteristics shall be described:

- absorption (rate and extent),

- distribution,

- metabolism,

- excretion.

Clinically significant features including the implication of the kinetic data for the dosage regimen especially for patients at risk, and differences between man and animal species used in the preclinical studies, shall be described.

3. Interactions

If the medicinal product is normally to be administered concomitantly with other medicinal products, particulars shall be given of joint administration tests performed to demonstrate possible modification of the pharmacological action.

If pharmacodynamic/pharmacokinetic interactions exist between the substance and other medical products or substances like alcohol, caffeine, tobacco or nicotine, likely to be taken simultaneously, or if such interactions are likely, they should be described and discussed; particularly from the point of view of clinical relevance and the relationship to the statement concerning interactions in the summary of product characteristics presented in accordance with Article 11 point 5.6.

E. Bioavailability/bioequivalence

The assessment of bioavailability must be undertaken in all cases where it is necessary, e.g. where the therapeutic dose is near the toxic dose or where the previous tests have revealed anomalies which may be related to pharmacodynamic properties, such as variable absorption.

In addition, an assessment of bioavailability shall be undertaken where necessary to demonstrate bioequivalence for the medicinal products referred to in Article 10(1)(a).

F. Clinical efficacy and safety

1. In general, clinical trials shall be done as .controlled clinical trials. and if possible, randomized; any other design shall be justified. The treatment of the control groups will vary from case to case and also will depend on ethical considerations; thus it may, in some instances, be more pertinent to compare the efficacy of a new 
medicinal product with that of an established medicinal product of proven therapeutic value rather than with the effect of a placebo.

As far as possible, and particularly in trials where the effect of the product cannot be objectively measured, steps shall be taken to avoid bias, including methods of randomization and blinding.

2. The protocol of the trial must include a thorough description of the statistical methods to be employed, the number and reasons for inclusion of patients (including calculations of the power of the trial), the level of significance to be used and a description of the statistical unit. Measures taken to avoid bias, particularly methods of randomization, shall be documented. Inclusion of a large number of subjects in a trial must not be regarded as an adequate substitute for a properly controlled trial.

3. Clinical statements concerning the efficacy or safety of a medicinal product under normal conditions of use which are not scientifically substantiated cannot be accepted as valid evidence.

28.11.2001 EN Official Journal of the European Communities L 311/117

4. The value of data on the efficacy and safety of a medicinal product under normal conditions of use will be very greatly enhanced if such data come from several competent investigators working independently.

5. For vaccines and serums, the immunological status and age of the trial population and the local epidemiology are of critical importance and shall be monitored during the trial and fully described.

For live attenuated vaccines, clinical trials shall be so designed as to reveal potential transmission of the immunizing agent from vaccinated to non-vaccinated subjects. If transmission is possible, the genotypic and phenotypic stability of the immunizing agent shall be studied.

For vaccines and allergen products, follow-up studies shall include appropriate immunological tests, and where applicable, antibody assays.

6. The pertinence of the different trials to the assessment of safety and the validity of methods of evaluation shall be discussed in the expert report.

7. All adverse events including abnormal laboratory values shall be presented individually and discussed, especially:

- in terms of overall adverse experience, and

- as a function of the nature, seriousness and causality of effects.

8. A critical assessment of relative safety, taking into account adverse reactions, shall be made in relation to:

- the disease to be treated,

- other therapeutic approaches,

- particular characteristics in sub-groups of patients,

- preclinical data on toxicology and pharmacology.

9. Recommendations shall be made for the conditions of use, with the intention of reducing the incidence of adverse reactions. 
G. Documentation for applications in exceptional circumstances

When, in respect of particular therapeutic indications, the applicant can show that he is unable to provide comprehensive data on the efficacy and safety under normal conditions of use, because:

- the indications for which the product in question is intended are encountered so rarely that the applicant cannot reasonably be expected to provide comprehensive evidence, or

- in the present state of scientific knowledge, comprehensive information cannot be provided, or

- it would be contrary to generally accepted principles of medical ethics to collect such information, marketing authorization may be granted on the following conditions:

(a) the applicant completes on identified programme of studies within a time period specified by the competent authority, the results of which shall form the basis of a reassessment of the benefit/risk profile,

(b) the medicinal product in question may be supplied on medical prescription only and may in certain cases be administered only under strict medical supervision, possibly in a hospital and for a radiopharmaceutical, by an authorized person,

(c) the package leaflet and any medical information shall draw the attention of the medical practitioner to the fact that the particulars available concerning the medicinal product in question are as yet inadequate in certain specified respects.

L 311/118 EN Official Journal of the European Communities 28.11.2001

H. Post-marketing experience

1. If the medicinal product is already authorized in other countries, information shall be given in respect of adverse drug reactions of the medicinal product concerned and medicinal products containing the same active substance(s), in relation to the usage rates if possible. Information from worldwide studies relevant to the safety of the medicinal product shall be included.

For this purpose, an adverse drug reaction is a reaction which is noxious and unintended and which occurs at doses normally used in man for prophylaxis, diagnosis or therapy of disease or for the modification of physiological function.

2. In the case of vaccines already authorized in other countries, information on the monitoring of vaccinated subjects to evaluate the prevalence of the disease in question as compared to nonvaccinated subjects shall be submitted, when available.

3. For allergen products, response in periods of increased antigen exposure shall be identified.

I. Well-established medicinal use

For the purpose of demonstrating, pursuant to Article 10(1)(a)(ii), that the component(s) of a medicinal product have a well established use, with recognised efficacy, the following specific rules shall apply:

(a) Factors which have to be taken into account in order to establish a .well established medicinal use. of components of medicinal products are the time over 
which a substance has been used, quantitative aspects of the use of the substance, the degree of scientific interest in the use of the substance (reflected in the published scientific literature) and the coherence of scientific assessments. Therefore different periods of time may be necessary for establishing .well established use. of different substances. In any case, however, the period of time required for establishing a .well established medicinal use. of a component of a medicinal product must not be less than one decade from the first systematic and documented use of that substance as a medicinal product in the Community.

(b) The documentation submitted by the applicant should cover all aspects of the efficacy assessment and must include or refer to a review of the relevant literature, taking into account pre- and postmarketing studies and published scientific literature concerning experience in the form of epidemiological studies and in particular of comparative epidemiological studies. All documentation, both favourable and unfavourable, should be communicated.

(c) Particular attention must be paid to any missing information and justification must be given why demonstration of efficacy can be supported although some studies are lacking.

(d) The Expert report must explain the relevance of any data submitted which concern a product different from the product intended for marketing. A judgment must be made whether the product studied can be considered as similar to the product which will be granted a marketing authorisation in spite of the existing differences.

(e) Post-marketing experience with other products containing the same components is of particular importance and applicants should put a special emphasis on this issue.

28.11.2001 EN Official Journal of the European Communities L 311/119

ANNEX II

\section{PART A}

Repealed Directives, with their successive amendments (referred to by Article 128)

Council Directive 65/65/EEC (OJ 22, 9. 2. 1965, p. 369/65)

Council Directive 66/454/EEC (OJ 144, 5. 8. 1966, p. 2658/66)

Council Directive 75/319/EEC (OJ L 147, 9. 6. 1975, p. 13)

Council Directive 83/570/EEC (OJ L 332, 28. 11. 1983, p. 1)

Council Directive 87/21/EEC (OJ L 15, 17. 1. 1987, p. 36)

Council Directive 89/341/EEC (OJ L 142, 25. 5. 1989, p. 11)

Council Directive 92/27/EEC (OJ L 113, 30. 4. 1992, p. 8)

Council Directive 93/39/EEC (OJ L 214, 24. 8. 1993, p. 22)

Council Directive 75/318/EEC (OJ L 147, 9. 6. 1975, p. 1)

Council Directive 83/570/EEC

Council Directive 87/19/EEC (OJ L 15, 17. 1. 1987, p. 31)

Council Directive 89/341/EEC

Commission Directive 91/507/EEC (OJ L 270, 26. 9. 1991, p. 32)

Council Directive 93/39/EEC

Commission Directive 1999/82/EC (OJ L 243, 15. 9. 1999, p. 7)

Commission Directive 1999/83/EC (OJ L 243, 15. 9. 1999, p. 9) 
Council Directive 75/319/EEC

Council Directive 78/420/EEC (OJ L 123, 11. 5. 1978, p. 26)

Council Directive 83/570/EEC

Council Directive 89/341/EEC

Council Directive 92/27/EEC

Council Directive 93/39/EEC

Commission Directive 2000/38/EC (OJ L 139, 10. 6. 2000, p. 28)

Council Directive 89/342/EEC (OJ L 142, 25. 5. 1989, p. 14)

Council Directive 89/343/EEC (OJ L 142, 25. 5. 1989, p. 16)

Council Directive 89/381/EEC (OJ L 181, 28. 6. 1989, p. 44)

Council Directive 92/25/EEC (OJ L 113, 30. 4. 1992, p. 1)

Council Directive 92/26/EEC (OJ L 113, 30. 4. 1992, p. 5)

Council Directive 92/27/EEC

Council Directive 92/28/EEC (OJ L 113, 30. 4. 1992, p. 13)

Council Directive 92/73/EEC (OJ L 297, 13. 10. 1992, p. 8)

L 311/120 EN Official Journal of the European Communities 28.11.2001

PART B

Time-limits for transposition into national law (referred to by Article 128)

Directive Deadline for transposition

Directive 65/65/EEC 31 December 1966

Directive 66/454/EEC .

Directive 75/318/EEC 21 November 1976

Directive 75/319/EEC 21 November 1976

Directive 78/420/EEC .

Directive 83/570/EEC 31 October 1985

Directive 87/19/EEC 1 July 1987

Directive 87/21/EEC 1 July 1987

1 January 1992 (1)

Directive 89/341/EEC 1 January 1992

Directive 89/342/EEC 1 January 1992

Directive 89/343/EEC 1 January 1992

Directive 89/381/EEC 1 January 1992

Directive 91/507/EEC 1 January 1992 (2)

1 January 1995 (3)

Directive 92/25/EEC 1 January 1993

Directive 92/26/EEC 1 January 1993

Directive 92/27/EEC 1 January 1993

Directive 92/28/EEC 1 January 1993

Directive 92/73/EEC 31 December 1993

Directive 93/39/EEC 1 January 1995 (4)

1 January 1998 (5)

Directive 1999/82/EC 1 January 2000

Directive 1999/83/EC 1 March 2000 
Directive 2000/38/EC 5 December 2001

(1) Deadline for transposition applicable to Greece, Spain and Portugal.

(2) Except Section A, point 3.3 in Part II of the Annex.

(3) Deadline for transposition applicable to Section A, point 3.3 in Part II of the Annex.

(4) Except with regard to Article 1(6).

(5) Deadline for transposition applicable to Article 1(7).

28.11.2001 EN Official Journal of the European Communities L 311/121

L 311/122 EN Official Journal of the European Communities 28.11.2001

ANNEX III

CORRELATION TABLE

This Dir. 65/65/EEC 75/318/EEC 75/319/EEC 89/342/EEC 89/343/EEC 89/381/EEC 92/25/EEC 92/26/EEC 92/27/EEC 92/28/EEC 92/73/EEC

Art. 1(1) to (3) Art. 1(1) to (3)

Art. 1(4) Annex Art. 1(1) and

(2)

Art. 1(5) Art. 1

Art. 1(6) to (9) Art. 1(2)

Art. 1(10) Art. 1(1)

Art. 1(11) to

(16)

Art. 29b, 1st

paragraph

Art. 1(17) and

(18)

Art. 1(2)

Art. 1(19) Art. 1(2), 2nd

sentence

Art. 1(20) to

(26)

Art. 1(2)

Art. 1(27) Art. 8(1)

Art. 1(28) Art. 10(1)

Art. 2 Art. 2(1)

Art. 3(1) and (2) Art. 1(4) and

(5)

Art 2(3), 1st

indent

Art. 3(3) and (4) Art.2(3), 2nd

and 3 rd indents

Art. 3(5) Art. 1(1)

Art. 3(6) Art. 1(2)

Art. 4(1) Art. 1(3) 
Art. 4(2) Art. 1(3)

Art. 4(3) Art. 3, 2nd

subparagraph

Art. 4(4) Art. 6

Art. 5 Art. 2(4)

Art. 6(1) Art. 3(1)

Art. 6(2) Art. 2, 1st

sentence

Art. 7 Art. 2, 2nd

sentence

Art. 8(1) and (2) Art. 4(1) and

(2)

Art. 8(3)(a) to

(e)

Art. 4, 3rd

para., points 1

to 5

Art. 1, 1st

paragraph

Art. 8(3)(f) to (i) Art. 4, 3rd

para., points 6

to 8.1

Art. 8(3)(j) to (1) Art. 4, 3rd

para., points 9

to 11

Art. 9 Art. 3

Art. 10(1) Art. 4, 3rd

paragraph,

point 8.2

Art. 10(2) Art. 1, 2nd

paragraph

Art. 11, points

1 to 5.3

Art. 4a, points

1 to 5.3

Art. 11, point

5.4

Art. $4 a$, point

5.4

Art. 3

Art. 11, points

5.5 to 6.4

Art. 4a, points 
5.5 to 6.4

Art. 11, point

6.5

Art. 4a, point

6.6

Art. 11 , point 7 Art. 4a, point

6.5

Art. 11, points

8 to 9

Art. 4

Art. 12(1) Art. 1

28.11.2001 EN Official Journal of the European Communities L 311/123

This Dir. 65/65/EEC 75/318/EEC 75/319/EEC 89/342/EEC 89/343/EEC 89/381/EEC 92/25/EEC 92/26/EEC 92/27/EEC 92/28/EEC 92/73/EEC

Art. 12(2) and

(3)

Art. 2

Art. 13 Art. 6(1) and (2)

Art. 14(1) and

(2)

Art. 7(1) and (4)

Art. 14(3) Art. 4, 2nd

paragraph

Art. 15 Art. 8

Art. 16 Art. 9

Art. 17 Art. 7

Art. 18 Art. 7a

Art. 19 Art. 4

Art. 20 Art. 5

Art. 21 Art. 4b

Art. 22 Art. 10(2)

Art. 23 Art. 9a

Art. 24 Art. 10(1)

Art. 25 Art. 9

Art. 26 Art. 5

Art. 27 Art. 8

Art. 28(1) Art. 9(3)

Art. 28(2) Art. 9(1)

Art. 28(3) Art. 9(2)

Art. 28(4) Art. 9(4)

Art. 29 Art. 10

Art. 30 Art. 11

Art. 31 Art. 12 
Art. 32 Art. 13

Art. 33 Art. 14(1)

Art. 34 Art. 14(2) to (4)

Art. 35 Art. 15

L 311/124 EN Official Journal of the European Communities 28.11.2001

Art. 36 Art. $15 \mathrm{a}$

Art. 37 Art. 15b

Art. 38 Art. $15 \mathrm{c}$

Art. 39 Art. 14(5)

Art. 40 Art. 16

Art. 41 Art. 17

Art. 42 Art. 18

Art. 43 Art. 20(1)

Art. 44 Art. 20(2)

Art. 45 Art. 20(3)

Art. 46 Art. 19

Art. 47 Art. 19a

Art. 48 Art. 21

Art. 49 Art. 23

Art. 50 Art. 24

Art. 51(1) and

(2)

Art. 22(1)

Art. 51(3) Art. 22(2)

Art. 52 Art. 25

Art. 53 Art. 3

Art. 54 Art. 2(1)

Art. 55 Art. 3

Art. 56 Art. 4(1)

Art. 57 Art. 5(2)

Art. 58 Art. 6

Art. 59 Art. 7(1) and

(2)

Art. 60 Art. 5(1) and

Art. 9

Art. 61 Art. 10(1) to (4)

Art. 62 Art. 2(2) and

Art. 7(3)

28.11.2001 EN Official Journal of the European Communities L 311/125

This Dir. 65/65/EEC 75/318/EEC 75/319/EEC 89/342/EEC 89/343/EEC 89/381/EEC 92/25/EEC 92/26/EEC 92/27/EEC 92/28/EEC 92/73/EEC

Art. 63(1) Art. 4(2)

Art. 63(2) Art. 8 
Art. 63(3) Art. 10(5)

Art. 64 Art. 11(1)

Art. 65 Art. 12

Art. 66 Art. 5

Art. 67 Art. 6(1)

Art. 68 Art. 2(2)

Art. 69 Art. 7(2) and (3)

Art. 70 Art. 2

Art. 71 Art. 3

Art. 72 Art. 4

Art. 73 Art. 5(1)

Art. 74 Art. 5(2)

Art. 75 Art. 6(2)

Art. 76 Art. 2

Art. 77 Art. 3

Art. 78 Art. 4(1)

Art. 79 Art. 5

Art. 80 Art. 6

Art. 81 Art. 7

Art. 82 Art. 8

Art. 83 Art. 9

Art. 84 Art. 10

Art. 85 Art. 9

Art. 86 Art. 1(3) and

(4)

Art. 87 Art. 2

Art. 88 Art. 3(1) to (6)

L 311/126 EN Official Journal of the European Communities 28.11.2001

Art. 89 Art. 4

Art. 90 Art. 5

Art. 91 Art. 6

Art. 92 Art. 7

Art. 93 Art. 8

Art. 94 Art. 9

Art. 95 Art. 10

Art. 96 Art. 11

Art. 97(1) to (4) Art. 12(1) and

(2)

Art. 97(5) Art. 12(4)

Art. 98 Art. 13

Art. 99 Art. 14

Art. 100 Art. 6(3)

Art. 101 Art. 29e 
Art. 102 Art. 29a

Art. 103 Art. 29c

Art. 104 Art. 29d

Art. 105 Art. 29f

Art. 106(1) Art. 29g

Art. 106(2) Art. 29b, 2nd

paragraph

Art. 107 Art. 29h

Art. 108 Art. 29i

Art. 109 Art. 3(1) to (3)

Art. 110 Art. 3(4)

Art. 111(1) Art. 26, 1st and

2nd paragraph

Art. 111(2) Art. 4(1)

Art. 111(3) Art. 26, 3rd

paragraph

28.11.2001 EN Official Journal of the European Communities L 311/127

This Dir. 65/65/EEC 75/318/EEC 75/319/EEC 89/342/EEC 89/343/EEC 89/381/EEC 92/25/EEC 92/26/EEC 92/27/EEC 92/28/EEC 92/73/EEC

Art. 112 Art. 8 Art. 27

Art. 113 Art. 4(2) Art. 4(2)

Art. 114(1) Art. 4(3)

Art. 114(2) Art. 4(3)

Art. 115 Art. 4(1)

Art. 116 Art. 11

Art. 117 Art. 28

Art. 118 Art. 29

Art. 119 Art. 4(1)

Art. 120 Art. 2a, 1st

paragraph

Art. 121 Art. $2 \mathrm{~b}$ Art. $37 \mathrm{a}$

Art. 122 Art. 30

Art. 123 Art. 33

Art. 124 Art. 5

Art. 125 Art. 12 Art. 31 Art. 4(2) Art. 11(2) Art. 12(3)

Art. 126, 1st

paragraph

Art. 21

Art. 126, 2nd

paragraph

Art. 32

Art. 127 Art. 28a

Art. $128 \ldots \ldots \ldots$. . . 
Art. 129

Annex I Annex

Annex II . . . . . . . . . . . . .

Annex III . . . . . . . . . . .

L 311/128 EN Official Journal of the European Communities 28.11.2001 